\title{
RAD sequencing enables unprecedented phylogenetic resolution and objective species delimitation in recalcitrant divergent taxa
}

\author{
Santiago Herrera ${ }^{1,2}$ (sherrera@alum.mit.edu) \\ Timothy M. Shank ${ }^{1}$ (tshank@whoi.edu) \\ ${ }^{1}$ Massachusetts Institute of Technology, Cambridge, MA, USA \\ ${ }^{2}$ Biology Department, Woods Hole Oceanographic Institution, Woods Hole, MA, USA
}

\begin{abstract}
Species delimitation is problematic in many taxa due to the difficulty of evaluating predictions from species delimitation hypotheses, which chiefly relay on subjective interpretations of morphological observations and/or DNA sequence data. This problem is exacerbated in recalcitrant taxa for which genetic resources are scarce and inadequate to resolve questions regarding evolutionary relationships and uniqueness. In this case study we demonstrate the empirical utility of restriction site associated DNA sequencing (RAD-seq) by unambiguously resolving phylogenetic relationships among recalcitrant octocoral taxa with divergences greater than 80 million years. We objectively infer robust species boundaries in the genus Paragorgia, which contains some of the most important ecosystem engineers in the deep-sea, by testing alternative taxonomy-guided or unguided species delimitation hypotheses using the Bayes factors delimitation method (BFD*) with genome-wide single nucleotide polymorphism data. We present conclusive evidence rejecting the current morphological species delimitation model for the genus Paragorgia and indicating the presence of cryptic species boundaries associated with environmental variables. We argue that the suitability limits of RAD-seq for phylogenetic inferences in divergent taxa cannot be assessed in terms of absolute time, but depend on taxon-specific factors such as mutation rate, generation time and effective population size. We show that classic morphological taxonomy can greatly benefit from integrative approaches that provide objective tests to species delimitation hypothesis. Our results pave the way for addressing further questions in biogeography, species ranges, community ecology, population dynamics, conservation, and evolution in octocorals and other marine taxa.
\end{abstract}

\section{INTRODUCTION}

Species delimitation is problematic in many taxa due to the difficulty of evaluating predictions from species delimitation hypotheses derived using different species concepts. Species concepts set particular expectations of the properties used to support species delimitations (De Queiroz 2007). For example, the classic biological species concept requires intrinsic reproductive isolation between heterospecific organisms and interbreeding among homospecific organisms resulting in viable and fertile descendants (Mayr 1942; Dobzhansky 1970). In many cases, if not the majority, it is difficult to evaluate behavioral, reproductive, and ecological properties due to technical limitations of field or laboratory work, which largely determine the kind of observations and data that can be obtained. In these cases researchers conventionally rely on morphological observations and/or DNA sequence data to generate species delimitation hypotheses.

Although there have been significant attempts at developing statistical methods to objectively identify species-diagnostic morphological discontinuities (e.g., Zapata \& Jimenez 2012), most species delimitations continue to be performed subjectively based on assessments made by specialized taxonomists. Molecular phylogenetic analyses of DNA sequences provide an independent way to test 
these species delimitation hypotheses utilizing a variety of methods, ranging from variability thresholds of barcode sequences (Hebert et al. 2003), to probabilistic coalescent-based model methods (Pons et al. 2006; Yang \& Rannala 2010; Fujisawa \& Barraclough 2013; Grummer et al. 2014). These molecular methods rely on informative DNA sequence markers, and in many cases on resolved phylogenies.

The sub-class Octocorallia (Phylum Cnidaria), which includes animals known as gorgonians, sea pens, and soft corals, is an example of a recalcitrant group where species delimitations are problematic. Octocorals are predominantly a deep-sea group (Cairns 2007; Roberts \& Cairns 2014) and therefore are extremely difficult to observe and collect. Classic morphology-based species delimitation and identification in this group is arduous for non-specialists, and challenging to replicate among taxonomists (Daly et al. 2007; McFadden et al. 2010b). Variations in octocoral colony architecture and micro-skeletal structures - sclerites - are used as species diagnostic characters (Bayer 1956). However, studies over the last 15 years have shown that in many cases species delimitations and systematics based on these morphological traits keep little to no correspondence with the patterns of genetic diversity and relatedness inferred using mitochondrial and ribosomal DNA sequence markers (McFadden et al. 2006; Clark et al. 2007; France 2007; Dueñas \& Sánchez 2009). A confounding factor when analyzing mitochondrial DNA markers is the fact that anthozoans, including octocorals, have slow rates of sequence evolution relative to other metazoans (Shearer et al. 2002; Hellberg 2006). Furthermore, octocoral mitochondrion is unique among eukaryotes by having a functional DNA mismatch repair gene - mtMutS - which presumably is responsible for the extremely low sequence variability observed in this group (Bilewitch \& Degnan 2011). Traditional molecular markers have thus been remarkably insufficient to resolve relationships at all taxonomic levels within the octocorals (Berntson et al. 2001; France et al. 2002; Mcfadden et al. 2004; Smith et al. 2004; Thoma et al. 2009; Dueñas et al. 2014). Alternative nuclear markers, such as the ITS2 and SRP54 have been used to examine interspecific and intraspecific relationships (Aguilar \& Sánchez 2007; Concepcion et al. 2007; Grajales et al. 2007; Herrera et al. 2010); however, their application and impact has been limited due to issues regarding intragenomic variability (Sanchez \& Dorado 2008) and low sequencing reliability (Mcfadden et al. 2010a). These long-standing technical problems have caused fundamental questions in octocorals regarding species differentiation, systematics, diversity, biogeography, and species ranges to remain unanswered.

Technological developments in next-generation sequencing platforms and library preparation methodologies have made genomic resources increasingly accessible and available for the study of nonmodel organisms, thus offering a great opportunity to overcome the difficulties inherent to the use of traditional sequencing approaches. One of these methodologies is restriction-site-associated DNA sequencing (RAD-seq), which combines enzymatic fragmentation of genomic DNA with high-throughput sequencing for the generation of large numbers of markers (Baird et al. 2008). RAD-seq has shown great promise to resolve difficult phylogenetic, phylogeographic, and species delimitation questions in diverse groups of eukaryotes (Emerson et al. 2010; Nadeau et al. 2012; Wagner et al. 2012; Eaton \& Ree 2013; Jones et al. 2013; Cruaud et al. 2014; Escudero et al. 2014; Hipp et al. 2014; Leache et al. 2014; Herrera et al. 2015), including cnidarians (Reitzel et al. 2013) and most recently deep-sea octocorals (Pante et al. 2014). The number of orthologous restriction sites that can be retained across taxa, which decreases as divergence increases, limits the usefulness of RAD-seq for these kinds of studies. In silico studies in model organisms indicate that RAD-seq can be used to infer phylogenetic relationships in young groups of species (up to 60 million years old), such as Drosophila (Rubin et al. 2012; Cariou et al. 2013; Seetharam \& Stuart 2013); however, the real limits of this technique have not been significantly explored.

In this study we aim to empirically explore the limits of RAD-seq to solve questions in phylogenetics and species delimitation. We focus on the recalcitrant Anthomastus-Corallium clade of octocorals (sensu McFadden et al. 2006) to test the utility of RAD-seq to resolve phylogenetic relationships among divergent taxa, and to infer objective species boundaries. Corals in the AnthomastusCorallium clade (hereafter referred as the AC clade) are among the most conspicuous, widely distributed, 
and ecologically important benthic invertebrates in deep-water ecosystems (Roberts et al. 2009; Wating et al. 2011). This clade is constituted by more than 100 species defined morphologically, divided in 10 genera, and three families (World Register of Marine Species at http://www.marinespecies.org accessed on 2014-10-10), spanning a divergence time of over 100 million years (Ardila et al. 2012; Herrera et al. 2012). However, species delimitations and phylogenetic relationships in this clade, as in other octocorals, are controversial and conflictive (Herrera et al. 2010; Ardila et al. 2012; Herrera et al. 2012). Many of the species in this group are considered species indicators of Vulnerable Marine Ecosystems (e.g. ICES 2013), with some of them considered endangered (CITES 2014). Accurate species identifications, as well as complete inventories and knowledge of species ranges, are therefore critical to ensure the effectiveness and appropriateness of conservation and management policies.

\section{RESULTS}

\section{Morphological species identifications}

Using current species descriptions, colony observations, and scanning electron microscopy of sclerites, we identified a total of 12 putative morphological species among the 44 examined specimens from the AC clade (Table S1, Supplementary Material images). These species correspond to the genera Paragorgia (P. arborea, P. stephencairnsi, P. johnsoni, P. maunga, P. alisonae, P. kaupeka, and P. coralloides) and Sibogagorgia (S. cauliflora) of the family Paragorgiidae; Hemicorallium (H. laauenseimperiale) and Corallium of the family Coralliidae; and Anthomastus and Heteropolypus of the family Alcyoniidae.

\section{Octocorals are amenable to $R A D$ sequencing}

We generated a dense genome-wide set of genetic markers from the $44 \mathrm{AC}$ clade specimens via RAD sequencing, using the 6-cutter restriction enzyme PstI, and used them to perform phylogenetic inferences and species delimitation analyses. We obtained roughly $3.9 \pm 1.4$ million reads (average \pm standard deviation) per individual, of which $74.3 \pm 8.1 \%$ were retained after stringent quality filtering steps (Table S2).

\section{Optimization of RAD-loci clustering parameters}

To examine the sensitivity of the phylogenetic inference to the clustering parameters used to identify loci and create nucleotide matrices in the program pyRAD (Eaton 2014), we investigated different combinations of clustering thresholds (c $0.80,0.85$ and 0.90$)$ and minimum number of taxa per

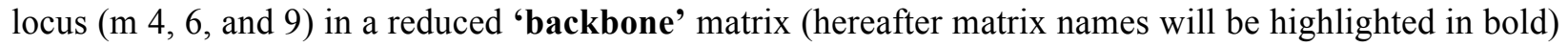
containing one individual from each of the 12 morphological species. The 9 resulting backbone matrices ranged in the total number of loci per matrix from approximately 9 to 60 thousand loci, increasing dramatically as the minimum number of taxa per locus was reduced (Table S3). In contrast, the different clustering thresholds did not have a significant effect on the total number of loci, but rather on the number of variable sites and, most importantly, on the number of phylogenetically informative sites (Table S3). Each resulting backbone matrix analyzed in RAxML (Stamatakis 2006) produced identical stronglysupported tree topologies (Fig S1). We selected c 0.80 ( $80 \%$ similarity among sequences) and $\mathrm{m} 9$ (minimum coverage of taxa per locus of $75 \%$ ) as the optimal combination of loci-clustering parameters because they minimized the proportion of missing data (0.20) in the matrix while maximizing the fraction of variable sites that were phylogenetically informative (0.24) (Table S3). The proportion of shared loci among individuals of Paragorgiidae and Coralliidae, lineages whose split has been estimated to be between 80-150 million years ago (Ardila et al. 2012; Herrera et al. 2012), was remarkably high (70$80 \%$ ) (Fig 1).

We used the selected optimal loci-clustering parameters to generate the 'PHYLO' matrix, containing the sequence data of all the 44 octocoral specimens. The use of the parameter value c 0.80 yielded approximately $71 \pm 15$ thousand loci - with a minimum depth of coverage of $5 \mathrm{x}$ and after filtering 
for paralogs- per specimen (mean depth of clusters used in loci construction was $23 \pm 8 x$ ) (Table S4). The PHYLO matrix contained a total of 5,997 loci that contained data for at least $75 \%$ of the specimens (after a second paralog removal). There were 85,293 variable sites in this matrix, of which 53,150 were phylogenetically informative.

\section{RAD-seq data support a fully resolved phylogeny}

The phylogenetic analysis of the PHYLO concatenated RAD-seq matrix produced a completely resolved evolutionary tree of the AC specimens (Fig 2). In general, all branches were supported by high (greater than 95) bootstrap values, except for the one supporting the clade of $P$. johnsoni, P. alisonae, and $P$. maunga. Each one of the morphologically identified families, genera, and species in this dataset were monophyletic. The branching pattern of the tree is consistent with an expected transition between coalescent processes among species and genera (long deep branches), and population processes within species (short shallow branches).

The topology of the tree obtained with a traditional 'mitochondrial' matrix (711 base pairs of the mtMutS gene containing 130 variable sites, of which 101 were phylogenetically informative) was incongruent with the PHYLO tree (Fig 2). The mitochondrial tree indicated a well-supported alternative divergence order for P. coralloides and P. kaupeka in the Paragorgia clade. In addition, the families Paragorgiidae (bubblegum corals) and Coralliidae (precious corals) were not monophyletic. The bubblegum coral genus Sibogagorgia appeared more closely related to the precious corals than to the other bubblegum coral genus Paragorgia, and the genera Corallium and Hemicorallium did not form a clade. However, these alternative relationships were not significantly supported by the bootstrap analysis,. Indeed, a substantial proportion of branches on the mitochondrial tree were poorly supported (bootstrap values smaller than $80 \%$ ).

\section{$R A D$-seq data reveal cryptic genetic diversity}

Branch-length differences among individuals, as well as well-supported sub-clades, revealed intraspecific genetic diversity that was undetected by the mitochondrial matrix. Two sub-clades were revealed by the phylogenetic analysis of the PHYLO matrix in the $P$. arborea and $P$. stephencairnsi clades. The sub-clades in $P$. arborea correspond to a pattern of segregation by geographic location with specimens from the north Pacific in one sub-clade, and specimens from the south Pacific and north Atlantic in the other. Contrastingly, the sub-clades in P. stephencairnsi correspond to a pattern of segregation by depth with specimens collected shallower than $350 \mathrm{~m}$ in one sub-clade, and specimens collected deeper than $1000 \mathrm{~m}$ in the other.

\section{Current morphological species delimitation is rejected}

To evaluate the utility of RAD-seq to perform objective species delimitations in octocorals we focused on specimens the genus Paragorgia as it was the best-sampled taxon in our dataset, both in terms of geographic representation and number of morphological species. We used the Bayes Factor Delimitation method with genomic data (BFD*) (Leache et al. 2014), which allows for the comparison of conflictive species delimitation models in an explicit multispecies coalescent framework using genomewide single nucleotide polymorphism (SNP) data. We calculated marginal likelihoods of taxonomyguided and taxonomy-unguided species delimitation models from a matrix of unlinked SNPs including only specimens of Paragorgia ('PARAGORGIA' matrix containing 1,203 SNPs present in all individuals). We compared the marginal likelihood estimates of alternative species delimitation models to the null model 'morphid', which is based on current morphological species descriptions, using Bayesian factors.

The null model, morphid, was rejected in favor of alternative species delimitation models for Paragorgia (Fig 3) (morphid was ranked $7^{\text {th }}$ among 10 evaluated models in terms of the marginal likelihood estimate). The 'PABSTE' model, which proposes 9 species based on the 7 morphological species in the dataset plus splits corresponding to the sub-clades in P. arborea and in P. stephencairnsi, 
received decisive support from Bayes factors as the best species delimitation model. The taxonomyunguided model 'geo' - which splits the specimens based on the geographic location where they were collected - and the models proposed by the Poisson tree processes (PTP) method based on the mitochondrial data matrix, were the lowest ranked and most strongly rejected models overall.

\section{Concatenated and coalescent species tree analyses are congruent}

The topology of the species tree inferred using the SNP PARAGORGIA matrix was entirely congruent with the topology generated by the maximum likelihood phylogenetic analysis of the concatenated sequence matrices (Fig 4). The species tree analysis also greatly improved support for the clade of $P$. johnsoni, $P$. alisonae, and P. maunga. The posterior distribution of species trees indicated a small fraction of conflictive topologies concentrating in this region of the tree.

\section{DISCUSSION}

\section{RAD sequencing enables unprecedented phylogenetic resolution}

Our analyses of RAD-seq data provide a robust phylogenetic hypothesis for the recalcitrant octocorals in the Anthomastus-Corallium clade, a result never achieved before. Moreover, this study, together with the work by Pante et al. (2014) in the octocoral genus Chrysogorgia, constitute the first applications of RAD-sequencing for phylogenetics and species delimitation in cnidarians. Only a handful of previous studies, using traditional mitochondrial data and the ITS2 and 28S nuclear markers, have attempted to evaluate phylogenetic relationships in the octocoral AC clade (Herrera et al. 2010; Ardila et al. 2012; Brockman \& McFadden 2012; Herrera et al. 2012; McFadden \& van Ofwegen 2013; Uda et al. 2013; Figueroa \& Baco 2014). These studies find support for the monophyly of the genus Paragorgia, the family Coralliidae, and the sister relationship between the Paragorgiidae and Coralliidae. However, those data do not provide enough phylogenetic resolution to infer the evolutionary relationships among many of the putative morphological species. Furthermore, significant incongruences between mitochondrial and nuclear ITS2 gene trees from AC taxa have been documented (Herrera et al. 2010). Here we reproduce similar incongruences when comparing the trees inferred from mitochondrial and RAD-seq datasets (Fig 2). Likewise, Pante et al. (2014) documented marked incongruence between trees inferred from mitochondrial and RAD-seq data in Chyrsogorgia. These observations suggest that processes that can cause gene tree heterogeneity, such as incomplete lineage sorting and horizontal gene transfer (Maddison 1997; Edwards 2009), may be more prevalent in octocorals than previously recognized.

All of our analyses based on RAD-seq matrices - varying in taxon coverage, degree of divergence among taxa, proportion of missing data, number of loci, and analysis type (concatenated or species tree) - produced completely congruent trees, which together provide extremely high confidence on the phylogenetic hypothesis inferred for the octocoral AC clade (Figs 1, 2 and 3). Consequently, we suggest that single marker gene trees in octocorals, particularly from the mitochondria, should not be considered as robust hypotheses of true species phylogenies on their own, without further validation by multiple informative and independent nuclear loci. We urge systematists to be conservative when making taxonomic rearrangements based on inferences from single-marker data alone.

\section{$R A D$-seq data is suitable for phylogenetic inference in divergent taxa}

Contrary to the currently accepted idea that RAD-seq data are only suitable for taxa with divergence times younger than 60 million years (MY) (Rubin et al. 2012), we demonstrate their suitability well beyond this age threshold. Remarkably, we were able to confidently resolve phylogenetic relationships among genera from different families diverging by at least $80 \mathrm{MY}$ in the AC clade. The split between the families Paragorgiidae and Coralliidae has been dated, using coralliid fossils, to be between 80-150 MY old (Ardila et al. 2012; Herrera et al. 2012). Park et al. (2012) estimated the age of the most recent common ancestor of the Coralliidae at approximately 50 MY (25-100 MY 95\% confidence region), using independent cnidarian fossils for molecular clock calibration. The split with the genera Anthomastus 
and Heteropolypus is likely older than $100 \mathrm{MY}$. It is without question that, due to evolution at restriction sites, the number of RAD loci among taxa for which orthology can be established decreases rapidly as divergence increases. However, we suggest that the suitability limits of RAD-seq for phylogenetics in divergent taxa cannot be assessed in terms absolute time, but depend on taxon-specific factors such as mutation rate, generation time and effective population size.

Bioinformatic studies addressing the issue of extent of the suitability of RAD-seq for phylogenetic inference have focused mainly on Drosophila as study model (Rubin et al. 2012; Cariou et al. 2013). Longer generation times and lower metabolic rates in taxa like deep-sea corals, relative to those in organisms like Drosophila, could cause a reduction in mutation rates (see review by Baer et al. (2007)), which may in turn decrease the evolutionary rates at restriction sites and allow for phylogenetic inferences using RAD-seq in situations of deeper divergence. Consistent with this hypothesis, we observe a nucleotide diversity $(\pi)$ calculated across all octocoral specimens from the PHYLO matrix of $0.012 \pm$ 0.002 (considered a minimum since RAD-seq can underestimate diversity (Arnold et al. 2013); see Table S5 and Table S6 for individual values), which is significantly lower than the nucleotide diversity in many of the Drosophila species included in the bioinformatic studies by Cariou et al. (2013) and Rubin et al. (2012). Nonetheless, there are other important factors known to influence genetic diversity across species - and likely the evolutionary rate as well. These factors include the effective population size, selection, habitat kind, geographic range, and mating system (Leffler et al. 2012). To sum up, we argue that RADseq can be successfully used to infer phylogenetic relationships in certain taxa with deeper divergences than previously suggested. This is particularly true when the number of RAD loci is maximized through the choice of restriction enzymes with higher cutting frequencies in the target taxon (Herrera et al. 2014).

\section{RAD-seq allows the formulation of robust species delineations}

Our study, the first statistical rigorous test of species hypothesis in octocorals, provides conclusive evidence rejecting the current morphological species delimitation model for the genus Paragorgia. We find decisive support for a nested model that combines species boundaries from morphological taxonomy with cryptic diversity linked to environmental variables of geographic location and depth (Figs 3 and 4). This nested model, proposes 9 species among the examined specimens. Five of these species correspond to the morphological species $P$. coralloides, $P$. kaupeka, $P$. alisonae, $P$. johnsoni, and $P$. maunga. Two splits, corresponding to sub-clades in the morphological species $P$. arborea and in P. stephencairnsi, indicate cases of cryptic species.

Herrera et al. (2012) found significant genetic differentiation of the north Pacific populations of $P$. arborea relative to the south Pacific, Atlantic and Indian ocean populations, and suggested that these populations may represent sub-species. The north Pacific populations of $P$. arborea were previously defined as a separate species, P. pacifica, by Verrill (1922) based on gross colony morphology, but later combined into a single species by Grasshoff (1979). Sánchez (2005) suggested potential small differences in medullar sclerite sizes and ornamentation between north Pacific specimens and specimens form elsewhere. However, we were unable to recognize these morphological differences in the few examined specimens in this study. Nonetheless, based on the decisive support for the split of $P$. arborea from analysis of genome-wide SNP makers indicates, we resurrect the species Paragorgia pacifica for the north Pacific populations of formerly P. arborea. We find no evidence of cryptic speciation between the north Atlantic and south Pacific P. arborea and therefore conclude it should be considered a single species as previously suggested by Herrera et al. (2012).

Depth is an important factor contributing to genetic differentiation and formation of species in the ocean, both shallow (Carlon \& Budd 2002; Prada \& Hellberg 2013) and deep (Miller et al. 2011; Jennings et al. 2013; Quattrini et al. 2013; Glazier \& Etter 2014). The observed cryptic differentiation between specimens of $P$. stephencairnsi collected shallower than $350 \mathrm{~m}$ and deeper than $1000 \mathrm{~m}$ indicates that depth is also a diversifying force in octocorals from the $\mathrm{AC}$ clade, which had gone undetected due to 
the low variability of traditional sequence data (Herrera et al. 2012). The holotype of P. stephencairnsi was collected from approximately $350 \mathrm{~m}$ in the Georgia Strait of British Columbia, overlapping in depth range and geographic region with that of most of the specimens from the shallow sub-clade examined in this study. Therefore, we propose to conserve that name $P$. stephencairnsi for that shallow sub-clade, and consider the deep sub-clade as a new species.

Other recent species delimitation studies in anthozoan corals have also revealed significant incongruences when comparing morphological and single-locus species delimitation hypotheses (particularly from mitochondrial data) with phylogenetic evidence from multi-locus datasets (Pante et al. 2014; Prada et al. 2014). In line with the findings of Pante et al. (2014), we find that specimens of Paragorgia sharing identical $m t M u t S$ haplotypes can belong to more than one species. Contrastingly, Herrera et al. (2012) present strong evidence showing significant mitochondrial haplotype diversity in the south Pacific and north Atlantic populations of Paragorgia arborea. Our observations, together with those from the aforementioned studies, constitute compelling evidence indicating that there is no solid basis for the widespread assumption that $m t M u t S$ haplotypes may be equivalent to individual octocoral species, as proposed by Thoma et al. (2009). The analysis with RAD-seq, or alternative genomic multilocus methods, of a larger number of specimens from diverse geographic locations and depth horizons will likely reveal further cryptic diversity not characterized by mitochondrial haploytypes (see Fig S2, Fig S3, and Table S8), and thus further illuminates taxonomy and systematics in this an other groups.

\section{CONCLUSIONS}

In this case study we demonstrate the empirical utility of RAD-seq to resolve phylogenetic relationships among divergent and recalcitrant taxa and to objectively infer species boundaries by testing alternative delimitation hypotheses. We were able to make use of RAD-seq to overcome long-standing technical difficulties in octocoral genetics, and to resolve fundamental questions in species definitions and systematics. We show that classic morphological taxonomy can greatly benefit from integrative approaches that provide objective tests to species delimitation hypothesis. Our results pave the way for addressing further questions in biogeography, species ranges, community ecology, population dynamics and evolution of octocorals and other marine taxa. The results from this study also represent a valuable reference resource for the development of tools, such as SNP arrays, that can be used to perform accurate species identifications, and generate species inventories that will aid the design and implementation of conservation and management policies.

\section{METHODS}

To perform identifications using current morphological species descriptions we performed colony observations and scanning electron microscopy of sclerites on 44 octocoral specimens from the AC clade (Table S1).

To obtain a genome-wide set of markers that could be useful for phylogenetic inferences of deepdivergent taxa and species delimitation in the AC clade (greater than 100 million years) we performed RAD sequencing with a the 6-cutter restriction enzyme PstI, which is predicted to cut between 32,000 and 110,000 times in the genome of an octocoral (Table S7). This predicted range was obtained using the observed frequency of the PstI recognition sequence, and its probability calculated using a trinucleotide composition model, in the genomes of the cnidarians Nematostella vectensis, Acropora digitifera, Hydra vulgaris, and Alatina moseri (Herrera et al. 2014). Genome size range of 0.3-0.5 pg was used based on observations obtained through flow cytometry in gorgoniid octocorals by Luisa Dueñas at the Universidad de los Andes, Bogotá, Colombia (personal communication). Total genomic DNA was purified from specimens following protocols described in Herrera et al. (2015). Concentration-normalized genomic DNA was submitted to Floragenex Inc (Eugene, OR). for library preparation and RAD 
sequencing. Libraries were sequenced by 48-multiplex, using 10-base pair barcodes, on a single lane of an Illumina Hi-Seq 2000 sequencer.

To compare the inferences obtained from RAD-seq data with the inferences drawn from traditional genetic barcoding data, we performed targeted sequencing of the mitochondrial $m t M u t S$ gene - a genetic marker widely used for phylogenetics and species delimitation studies in octocorals. Polymerase chain reactions were carried out following the protocols by Herrera et al. (2015). Primer pairs used for amplifications were AnthoCorMSH (Herrera et al. 2010) and Mut-3458R (Sánchez et al. 2003). Negative controls were included in every experiment to test for contamination. Purified PCR products were submitted to Eurofins Genomics (Eurofins MWG Operon, Inc.) for sequencing.

\section{RAD-seq data filtering}

Sequence reads were de-multiplexed and quality filtered with the process_radtags program from the package Stacks v1.20 (Catchen et al. 2013). Barcodes and Illumina adapters were excluded from each read and length was truncated to 91bp (-t 91) Reads with ambiguous bases were discarded (-c). Reads with an average quality score below 10 (-s 10) within a sliding window of $15 \%$ of the read length (-w $0.15)$ were discarded (-r). The rescue barcodes and RAD-tags algorithm was enabled (-r). Additional filtering, and the clustering within and between individuals to identify loci was performed using the program pyRAD v2.01 (Eaton 2014). Reads with more than 33 bases with a quality score below 20 were discarded.

\section{$R A D$-seq loci clustering and phylogenetic inference}

We investigated different combinations of clustering thresholds (c $0.80,0.85$ and 0.90 ) and minimum number of taxa per locus $(\mathrm{m} 4,6$, and 9) in a reduced dataset that included one individual from each of the 12 putative morphological species. The minimum depth of coverage required to build a cluster and the maximum number of shared polymorphic sites in a locus were kept constant at 4 (d) and 3 (p) respectively. Loci sequences were concatenated into combined matrices. We refer to these 9 resulting matrices as the 'backbone' matrices. Each of the resulting backbone matrices was analyzed in RAxMLHPC2 v8.0 (Stamatakis 2006) for maximum likelihood (ML) phylogenetic tree inference. For this, and all the other phylogenetic analyses in RAxML, we assumed a generalized time-reversible DNA substitution model with a gamma-distributed rate variation across sites (GTR GAMMA). Branch support was assessed by 500 bootstrap replicates.

We selected an optimal combination of loci clustering parameters as the set of parameters that minimized the number of missing data and maximized the number of phylogenetically informative sites while producing a highly supported phylogenetic tree. The optimal set of parameters chosen was a clustering threshold of $80 \%$ similarity among sequences (c 0.80 ) and a minimum coverage of taxa per locus of $75 \%$ (m 9). A concatenated matrix containing the sequence data of all the 44 octocoral specimens, denominated 'PHYLO', was built using this parameter combination (c 0.80, m 33) in pyRAD and subsequently analyzed in RAxML.

\section{Phylogenetic inference with traditional genetic barcoding data}

To compare the tree topology obtained from the phylogenetic inferences of the PHYLO RADseq dataset with traditional genetic barcoding data we analyzed the 'mitochondrial' dataset (containing the $m t M u t S$ sequences) using RAxML. These two datasets - PHYLO and mitochondrial - contain data from the same individuals. To place the specimens from this study in a broader phylogenetic context we also analyzed the mitochondrial dataset in RAxML with the addition of $m t M u t S$ data from 233 additional specimens belonging to the AC clade, as well as outgroups (see Table S8, Fig S2, and Fig S3).

\section{Testing species delimitation models for Paragorgia}


We constructed 5 taxonomy-guided species delimitation models for Paragorgia: i) 'morphid' model: 7 species based on current morphological species descriptions (Sánchez 2005); ii) 'PAB' model: 8 species based on the 7 morphological species plus a split of $P$. arborea based on previous evidence of genetic differentiation of north Pacific populations (Herrera et al. 2012); iii) 'STE' model: 8 species based on the 7 morphological species plus a split of $P$. stephencairnsi based on depth differences (specimens collected $<350 \mathrm{~m}$ vs. $>1000 \mathrm{~m}$ ), as depth is known to be an important structuring variable in marine taxa (Jennings et al. 2013; Prada \& Hellberg 2013; Quattrini et al. 2013); iv) 'PABSTE' model: 9 species based on the 7 morphological species plus the splits of the PAB and STE models; v) 'splitPAB' model: 10 species based on the 7 morphological species plus the split of the STE model and an additional split in the PAB model where $P$. arborea is split in 3 species corresponding to the ocean basin where the specimens were collected (north Pacific, south Pacific and north Atlantic).

We also generated taxonomy-unguided species delimitation models for Paragorgia through Bayesian and ML implementations of the Poisson tree processes model (PTP) (available at http://species.h-its.org/ptp/). PTP estimates the number of speciation events in a rooted phylogenetic tree in terms of nucleotide substitutions (Zhang et al. 2013). We used PTP to analyze the trees obtained from phylogenetic inferences in RAxML of reduced $m t M u t S$ and RAD-seq datasets that include only members of the family Paragorgiidae (genera Paragorgia and Sibogagorgia). The 'PARAGORGIIDAE' RADseq concatenated matrix was generated in pyRAD using a clustering threshold of $80 \%$ similarity among sequences (c 0.80 ) and a minimum coverage of taxa per locus of $100 \%(\mathrm{~m} \mathrm{33})$. The resulting phylogenetic trees of Paragorgia were rooted with the specimens of Sibogagorgia and analyzed by the PTP method using a Markov Chain Monte Carlo (MCMC) chain length of 500,000 generations (100 thinning, 25\% burnin). We assessed convergence by examining the likelihood trace. The combinations of the ML or Bayesian PTP implementations (mlPTP and bPTP, respectively) with the $m t M u t S$ or RAD-seq trees of Paragorgia resulted in four species delimitation models: i) 'mIPTPmt' model; ii) 'bPTPmt' model; iii) 'mIPTPrad' model; and iv) 'bPTPrad' model. Lastly, because deep-sea corals are known to show genetic differentiation at ocean basin/regional scales (Miller et al. 2011; Morrison et al. 2011; Herrera et al. 2012), we constructed an additional taxonomy-unguided species delimitation model - the 'geo' model - based on the geographic location where the specimens were collected (north Pacific, south Pacific or north Atlantic ocean basins).

To estimate the marginal likelihood of each species delimitation model we generated a matrix including only specimens of Paragorgia, denominated 'PARAGORGIA' using a clustering threshold of $80 \%$ similarity among sequences (c 0.80 ) and a minimum coverage of taxa per locus of $100 \%$ (m 31$)$ in pyRAD. In contrast to the backbone, PHYLO, and PARAGORGIIDAE RAD-seq matrices, this matrix contained the data of one SNP per locus and not the entire locus sequence. We analyzed these data using the implementation of BFD* in the SNAPP (Bryant et al. 2012) plug-in for the program BEAST v2.1.3 (Bouckaert et al. 2014). We performed a path-sampling of 48 steps, with a MCMC chain length of 100,000 (10,000 pre-burnin), following the guidelines from Leache et al. (2014). Bayesian factors were calculated from the marginal likelihood estimates for each model and compared using the framework proposed by Kass and Raftery (1995)

\section{Species tree inference}

To test the tree topology in the genus Paragorgia obtained by the phylogenetic analysis of the PHYLO and PARAGORGIIDAE concatenated matrices we performed a species tree inference from the SNP data in the PARAGORGIA matrix using the program SNAPP. This program allows the inference of species trees from unlinked SNP data (only one SNP per locus retained) bypassing the inference of individual gene trees (Bryant et al. 2012). We performed 3 independent runs using a MCMC chain length of 10,000,000 (sampling every 1,000 generations; pre-burnin of 1,000) with default prior distributions for coalescence rate, mutation rate and ancestral population size parameters. We assessed convergence to stationary distributions and effective sample sizes $>200$ after $10 \%$ burnin in the program TRACER 
(Rambaut \& Drummond 2007). Species trees in the posterior distribution were summarized with the program DENSITREE v2.01 (Bouckaert 2010).

\section{ACKNOWLEDGEMENTS}

This research was supported by the National Geographic Society/Waitt Foundation (W285-13 to $\mathrm{SH}$ ); the National Oceanic and Atmospheric Administration (NA09OAR4320129 to TS); the National Science Foundation (OCE-1131620 to TS); the National Aeronautics and Space Administration (NNX09AB76G to TS); and the Academic Programs Office (Ocean Ventures Fund to SH), the Ocean Exploration Institute (Fellowship support to TMS) and the Ocean Life Institute of the Woods Hole Oceanographic Institution (WHOI).

Specimens provided by the National Institute of Water and Atmospheric Research (NIWA) were collected under research programs: Kermadec Arc Minerals, funded by the New Zealand Ministry of Business, Innovation \& Employment (MBIE), Auckland University, Institute of Geological and Nuclear Science (GNS), and WHOI; Ocean Survey 20/20 funded by Land Information New Zealand; Impact of resource use on vulnerable deep-sea communities (CO1X0906), funded by MBIE; Nascent Inter-Ridge Volcanic And Neotectonic Activity, funded by the Ministry for Primary Industries (MPI), GNS, MBIE, and the U. of New Hampshire; Scientific Observer Program funded by MPI; and the Joint New ZealandUSA 2005 NOAA Ring of Fire Expedition, part of NIWA's Seamount Program (FRST CO1X0508). For enabling access to key specimens we thank K. Schnabel (NIWA), S. Mills (NIWA), D. Tracey (NIWA), M. Clark (NIWA), A. Rowden (NIWA), S. Cairns (Smithsonian), E. Cordes (Temple U.), A. Quattrini (Temple U.), G. Workman (Department of Fisheries and Oceans Canada - DFO), M. Wyeth (DFO), K. Anderson (DFO), M. Frey (Royal British Columbia Museum - RBCM), H. Gartner (RBCM), L. Watling (U. Hawaii), J. Adkins (CalTech). We thank P. Aldersdale (CSIRO), N. Ardila (ECOMAR) and J. Sanchez (U. Andes) for assistance with morphological identifications. We also thank E. O'Brien (WHOI), D. Forsman (WHOI), J. Fellows (WHOI), J. \& S. Schooner, K. Heylar, and N. McDaniel for invaluable assistance during scuba diving fieldwork in British Columbia (DFO scientific license FIN130270). We thank the chief scientists, masters, crew, scientific personnel, and funding agencies of expeditions AT0735, KOK0506, Lophelia II 2009, RB-0503, TAN1007, TAN1104, TAN1206, and TAN1213. We also thank A. Tarrant and A. Reitzel for providing helpful comments that improved this manuscript.

\section{REFERENCES}

Aguilar C, Sánchez JA (2007) Phylogenetic hypotheses of gorgoniid octocorals according to ITS2 and their predicted RNA secondary structures. Molecular Phylogenetics and Evolution 43, 774-786.

Ardila NE, Giribet G, Sanchez JA (2012) A time-calibrated molecular phylogeny of the precious corals: reconciling discrepancies in the taxonomic classification and insights into their evolutionary history. BMC Evolutionary Biology 12.

Arnold B, Corbett-Detig RB, Hartl D, Bomblies K (2013) RADseq underestimates diversity and introduces genealogical biases due to nonrandom haplotype sampling. Molecular Ecology 22, 3179-3190.

Baer CF, Miyamoto MM, Denver DR (2007) Mutation rate variation in multicellular eukaryotes: causes and consequences. Nature Reviews Genetics 8, 619-631.

Baird NA, Etter PD, Atwood TS, et al. (2008) Rapid SNP discovery and genetic mapping using sequenced RAD markers. PLoS One 3, 3376.

Bayer FM (1956) Octocorallia. In: Treatise on Invertebrate Paleontology Part F. Coelenterata (ed. Moore RC), pp. 163-231. Geological Society of America and University of Kansas Press, Lawrence, Kansas. 
Berntson EA, Bayer FM, McArthur AG, France SC (2001) Phylogenetic relationships within the Octocorallia (Cnidaria: Anthozoa) based on nuclear 18S rRNA sequences. Marine Biology 138, 235-246.

Bilewitch JP, Degnan SM (2011) A unique horizontal gene transfer event has provided the octocoral mitochondrial genome with an active mismatch repair gene that has potential for an unusual selfcontained function. BMC Evolutionary Biology 11, 228.

Bouckaert R, Heled J, Kuhnert D, et al. (2014) BEAST 2: a software platform for Bayesian evolutionary analysis. PLoS Comput Biol 10, e1003537.

Bouckaert RR (2010) DensiTree: making sense of sets of phylogenetic trees. Bioinformatics 26, 13721373.

Brockman SA, McFadden CS (2012) The mitochondrial genome of Paraminabea aldersladei (Cnidaria: Anthozoa: Octocorallia) supports intramolecular recombination as the primary mechanism of gene rearrangement in octocoral mitochondrial genomes. Genome Biology and Evolution 4, 9941006.

Bryant D, Bouckaert R, Felsenstein J, Rosenberg NA, RoyChoudhury A (2012) Inferring species trees directly from biallelic genetic markers: Bypassing gene trees in a full coalescent analysis. Molecular Biology and Evolution 29, 1917-1932.

Cairns S (2007) Deep-water corals: An overview with special reference to diversity and distribution of deep-water scleractinian corals. Bulletin of Marine Science 81, 311-322.

Cariou M, Duret L, Charlat S (2013) Is RAD-seq suitable for phylogenetic inference? An in silico assessment and optimization. Ecology and Evolution 3, 846-852.

Carlon DB, Budd AF (2002) Incipient speciation across a depth gradient in a scleractinian coral? Evolution 56, 2227-2242.

Catchen J, Hohenlohe PA, Bassham S, Amores A, Cresko WA (2013) Stacks: an analysis tool set for population genomics. Molecular Ecology 22, 3124-3140.

CITES (2014) Appendices I, II and III. Convention on International Trade in Endangered Species of wild fauna and flora, , http://www.cites.org/sites/default/files/eng/app/2014/E-Appendices-2014-0914.pdf.

Clark AG, Eisen MB, Smith DR, et al. (2007) Evolution of genes and genomes on the Drosophila phylogeny. Nature 450, 203-218.

Concepcion GT, Crepeau MW, Wagner D, Kahng SE, Toonen RJ (2007) An alternative to ITS, a hypervariable, single-copy nuclear intron in corals, and its use in detecting cryptic species within the octocoral genus Carijoa. Coral reefs 27, 323-336.

Cruaud A, Gautier M, Galan M, et al. (2014) Empirical assessment of RAD sequencing for interspecific phylogeny. Molecular Biology and Evolution 31, 1272-1274.

Daly M, Brugler MR, Cartwright P, et al. (2007) The phylum Cnidaria: A review of phylogenetic patterns and diversity 300 years after Linnaeus. Zootaxa 1668, 127-182.

De Queiroz K (2007) Species concepts and species delimitation. Systematic Biology 56, 879-886.

Dobzhansky T (1970) Genetics of the Evolutionary Process Columbia University Press, New York,

Dueñas LF, Alderslade P, Sánchez JA (2014) Molecular systematics of the deep-sea bamboo corals (Octocorallia: Isididae: Keratoisidinae) from New Zealand with descriptions of two new species of Keratoisis. Molecular Phylogenetics and Evolution 74, 15-28.

Dueñas LF, Sánchez JA (2009) Character lability in deep-sea bamboo corals (Octocorallia, Isididae, Keratoisidinae). Marine Ecology Progress Series 397, 11-23.

Eaton DA (2014) PyRAD: Assembly of de novo RADseq loci for phylogenetic analyses. Bioinformatics 30, 1844-1849.

Eaton DAR, Ree RH (2013) Inferring phylogeny and introgression using RADseq data: An example from flowering plants (Pedicularis: Orobanchaceae). Systematic Biology 62, 689-706.

Edwards SV (2009) Is a new and general theory of molecular systematics emerging? Evolution 63, 1-19. 
Emerson KJ, Merz CR, Catchen JM, et al. (2010) Resolving postglacial phylogeography using highthroughput sequencing. Proceedings of the National Academy of Sciences of the United States of America 107, 16196-16200.

Escudero M, Eaton DAR, Hahn M, Hipp AL (2014) Genotyping-by-sequencing as a tool to infer phylogeny and ancestral hybridization: A case study in Carex (Cyperaceae). Molecular Phylogenetics and Evolution 79, 359-367.

Figueroa DF, Baco AR (2014) Complete mitochondrial genomes elucidate phylogenetic relationships of the deep-sea octocoral families Coralliidae and Paragorgiidae. Deep-Sea Research Part Ii-Topical Studies in Oceanography 99, 83-91.

France SC (2007) Genetic analysis of bamboo corals (Cnidaria : Octocorallia : Isididae): Does lack of colony branching distinguish Lepidisis from Keratoisis? In: Bulletin of Marine Science, pp. 323333.

France SC, Hoover LL, Hoover LL (2002) DNA sequences of the mitochondrial COI gene have low levels of divergence among deep-sea octocorals (Cnidaria: Anthozoa). Hydrobiologia 471, 149155.

Fujisawa T, Barraclough TG (2013) Delimiting species using single-locus data and the generalized mixed Yule coalescent approach: A revised method and evaluation on simulated data sets. Systematic Biology 62, 707-724.

Glazier AE, Etter RJ (2014) Cryptic speciation along a bathymetric gradient. Biological Journal of the Linnean Society 113, 897-913.

Grajales A, Aguilar C, Sánchez JA (2007) Phylogenetic reconstruction using secondary structures of Internal Transcribed Spacer 2 (ITS2, rDNA): finding the molecular and morphological gap in Caribbean gorgonian corals. BMC Evolutionary Biology 7, 90.

Grasshoff M (1979) Zur bipolaren verbreitung der oktokoralle Paragorgia arborea (Cnidaria: Anthozoa: Scleraxonia). Senckenbergiana Maritima 11, 115-137.

Grummer JA, Bryson RW, Reeder TW (2014) Species delimitation using Bayes factors: Simulations and application to the Sceloporus scalaris species group (Squamata: Phrynosomatidae). Systematic Biology 63, 119-133.

Hebert PDN, Cywinska A, Ball SL, DeWaard JR (2003) Biological identifications through DNA barcodes. Proceedings of the Royal Society B-Biological Sciences 270, 313-321.

Hellberg ME (2006) No variation and low synonymous substitution rates in coral mtDNA despite high nuclear variation. BMC Evolutionary Biology 6.

Herrera S, Baco A, Sánchez JA (2010) Molecular systematics of the bubblegum coral genera (Paragorgiidae, Octocorallia) and description of a new deep-sea species. Molecular Phylogenetics and Evolution 55, 123-135.

Herrera S, Reyes-Herrera PH, Shank TM (2014) Genome-wide predictability of restriction sites across the eukaryotic tree of life. bioRxiv preprint doi: http://dx.doi.org/10.1101/007781

Herrera S, Shank TM, Sánchez JA (2012) Spatial and temporal patterns of genetic variation in the widespread antitropical deep-sea coral Paragorgia arborea. Molecular Ecology 21, 6053-6067.

Herrera S, Watanabe H, Shank T (2015) Evolutionary and biogeographical patterns of barnacles from deep-sea hydrothermal vents. Molecular Ecology, 24: 673-689.

Hipp AL, Eaton DAR, Cavender-Bares J, et al. (2014) A framework phylogeny of the american oak clade based on sequenced RAD data. PLoS One 9, e93975.

ICES (2013) Assessment of the list of VME indicator species and elements. International Council for the Exploration of the Sea, http://www.ices.dk/sites/pub/Publication Reports/Advice/2013/Special requests/NEAFC VME indicator species and elements.pdf.

Jennings RM, Etter RJ, Ficarra L (2013) Population differentiation and species formation in the deep sea: the potential role of environmental gradients and depth. PLoS One 8, e77594.

Jones JC, Fan S, Franchini P, Schartl M, Meyer A (2013) The evolutionary history of Xiphophorus fish and their sexually selected sword: a genome-wide approach using restriction site-associated DNA sequencing. Molecular Ecology 22, 2986-3001. 
Kass RE, Raftery AE (1995) Bayes Factors. Journal of the American Statistical Association 90, 773-795. Leache AD, Fujita MK, Minin VN, Bouckaert RR (2014) Species Delimitation using Genome-Wide SNP Data. Systematic Biology 63, 534-542.

Leffler EM, Bullaughey K, Matute DR, et al. (2012) Revisiting an old riddle: What determines genetic diversity levels within species? PLoS Biology 10, e1001388.

Maddison WP (1997) Gene trees in species trees. Systematic Biology 46, 523-536.

Mayr E (1942) Systematics and the Origin of Species from the Viewpoint of a Zoologist Columbia University Press, New York,

Mcfadden CS, Benayahu Y, Pante E, et al. (2010a) Limitations of mitochondrial gene barcoding in Octocorallia. Molecular Ecology Resources 11, 19-31.

McFadden CS, France SC, Sánchez JA, Alderslade P (2006) A molecular phylogenetic analysis of the Octocorallia (Cnidaria: Anthozoa) based on mitochondrial protein-coding sequences. Molecular Phylogenetics and Evolution 41, 513-527.

McFadden CS, Sanchez JA, France SC (2010b) Molecular Phylogenetic Insights into the Evolution of Octocorallia: A Review. Integrative and Comparative Biology 50, 389-410.

Mcfadden CS, Tullis ID, Breton Hutchinson M, Winner K, Sohm JA (2004) Variation in Coding (NADH Dehydrogenase Subunits 2, 3, and 6) and Noncoding Intergenic Spacer Regions of the Mitochondrial Genome in Octocorallia (Cnidaria: Anthozoa). Marine Biotechnology 6, 516-526.

McFadden CS, van Ofwegen LP (2013) Molecular phylogenetic evidence supports a new family of octocorals and a new genus of Alcyoniidae (Octocorallia, Alcyonacea). Zookeys 346, 59-83.

Miller KJ, Rowden AA, Williams A, Haussermann V (2011) Out of their depth? Isolated deep populations of the cosmopolitan coral Desmophyllum dianthus may be highly vulnerable to environmental change. PLoS One 6, e19004.

Morrison CL, Ross SW, Nizinski MS, et al. (2011) Genetic discontinuity among regional populations of Lophelia pertusa in the North Atlantic Ocean. Conservation Genetics 12, 713-729.

Nadeau NJ, Martin SH, Kozak KM, et al. (2012) Genome-wide patterns of divergence and gene flow across a butterfly radiation. Molecular Ecology 22, 814-826.

Pante E, Abdelkrim J, Viricel A, Gey D, France S (2014) Use of RAD sequencing for delimiting species. Heredity.

Park E, Hwang DS, Lee JS, et al. (2012) Estimation of divergence times in cnidarian evolution based on mitochondrial protein-coding genes and the fossil record. Molecular Phylogenetics and Evolution 62, 329-345.

Pons J, Barraclough TG, Gomez-Zurita J, et al. (2006) Sequence-based species delimitation for the DNA taxonomy of undescribed insects. Systematic Biology 55, 595-609.

Prada C, DeBiasse MB, Neigel JE, et al. (2014) Genetic species delineation among branching Caribbean Porites corals. Coral Reefs 33, 1019-1030.

Prada C, Hellberg ME (2013) Long prereproductive selection and divergence by depth in a Caribbean candelabrum coral. Proceedings of the National Academy of Sciences of the United States of America 110, 3961-3966.

Quattrini AM, Georgian SE, Byrnes L, et al. (2013) Niche divergence by deep-sea octocorals in the genus Callogorgia across the continental slope of the Gulf of Mexico. Molecular Ecology 22, 41234140.

Rambaut A, Drummond AJ (2007) Tracer v1.4, Available from http://beast.bio.ed.ac.uk/Tracer.

Reitzel AM, Herrera S, Layden MJ, Martindale MQ, Shank TM (2013) Going where traditional markers have not gone before: utility of and promise for RAD sequencing in marine invertebrate phylogeography and population genomics. Molecular Ecology 22, 2953-2970.

Roberts JM, Cairns SD (2014) Cold-water corals in a changing ocean. Current Opinion in Environmental Sustainability 7, 118-126.

Roberts JM, Wheeler A, Freiwald AR, Cairns SD (2009) Cold-Water Corals : The Biology and Geology of Deep-Sea Coral Habitats Cambridge University Press, Cambridge, UK ; New York. 
Rubin BE, Ree RH, Moreau CS (2012) Inferring phylogenies from RAD sequence data. PLoS One 7, e33394.

Sánchez JA (2005) Systematics of the bubblegum corals (Cnidaria: Octocorallia: Paragorgiidae) with description of new species from New Zealand and the Eastern Pacific. Zootaxa 1014, 1-72.

Sanchez JA, Dorado D (2008) Intragenomic ITS2 variation in Caribbean seafans. In: Proceedings of the 11 th International Coral Reef Symposium, pp. 1383-1387, Ft. Lauderdale.

Sánchez JA, Lasker HR, Taylor DJ (2003) Phylogenetic analyses among octocorals (Cnidaria): mitochondrial and nuclear DNA sequences (lsu-rRNA, 16S and ssu-rRNA, 18S) support two convergent clades of branching gorgonians. Molecular Phylogenetics and Evolution 29, 31-42.

Seetharam AS, Stuart GW (2013) Whole genome phylogeny for 21 Drosophila species using predicted 2b-RAD fragments. PeerJ 1, e226.

Shearer TL, Van Oppen MJH, Romano SL, Worheide G (2002) Slow mitochondrial DNA sequence evolution in the Anthozoa (Cnidaria). Molecular Ecology 11, 2475-2487.

Smith P, McVeagh S, Mingoia J, France S (2004) Mitochondrial DNA sequence variation in deep-sea bamboo coral (Keratoisidinae) species in the southwest and northwest Pacific Ocean. Marine Biology 144, 253-261.

Stamatakis A (2006) RAxML-VI-HPC: Maximum likelihood-based phylogenetic analyses with thousands of taxa and mixed models. Bioinformatics 22, 2688-2690.

Thoma J, Pante E, Brugler M, France S (2009) Deep-sea octocorals and antipatharians show no evidence of seamount-scale endemism in the NW Atlantic. Marine Ecology Progress Series 397, 25-35.

Uda K, Komeda Y, Fujita T, et al. (2013) Complete mitochondrial genomes of the Japanese pink coral (Corallium elatius) and the Mediterranean red coral (Corallium rubrum): a reevaluation of the phylogeny of the family Coralliidae based on molecular data. Comparative Biochemistry and Physiology D-Genomics \& Proteomics 8, 209-219.

Verrill AE (1922) Part G: Alcyonaria and Actiniaria. Report of the Canadian Arctic Expedition 1913-18 8, 1-164.

Wagner CE, Keller I, Wittwer S, et al. (2012) Genome-wide RAD sequence data provide unprecedented resolution of species boundaries and relationships in the Lake Victoria cichlid adaptive radiation. Molecular Ecology 22, 787-798.

Wating L, France SC, Pante E, Simpson A (2011) Biology of deep-water octocorals. Advances in Marine Biology, Vol 60 60, 41-122.

Yang ZH, Rannala B (2010) Bayesian species delimitation using multilocus sequence data. Proceedings of the National Academy of Sciences of the United States of America 107, 9264-9269.

Zapata F, Jimenez I (2012) Species delimitation: Inferring gaps in morphology across geography. Systematic Biology 61, 179-194.

Zhang J, Kapli P, Pavlidis P, Stamatakis A (2013) A general species delimitation method with applications to phylogenetic placements. Bioinformatics 29, 2869-2876. 


\section{FIGURES \& TABLES}

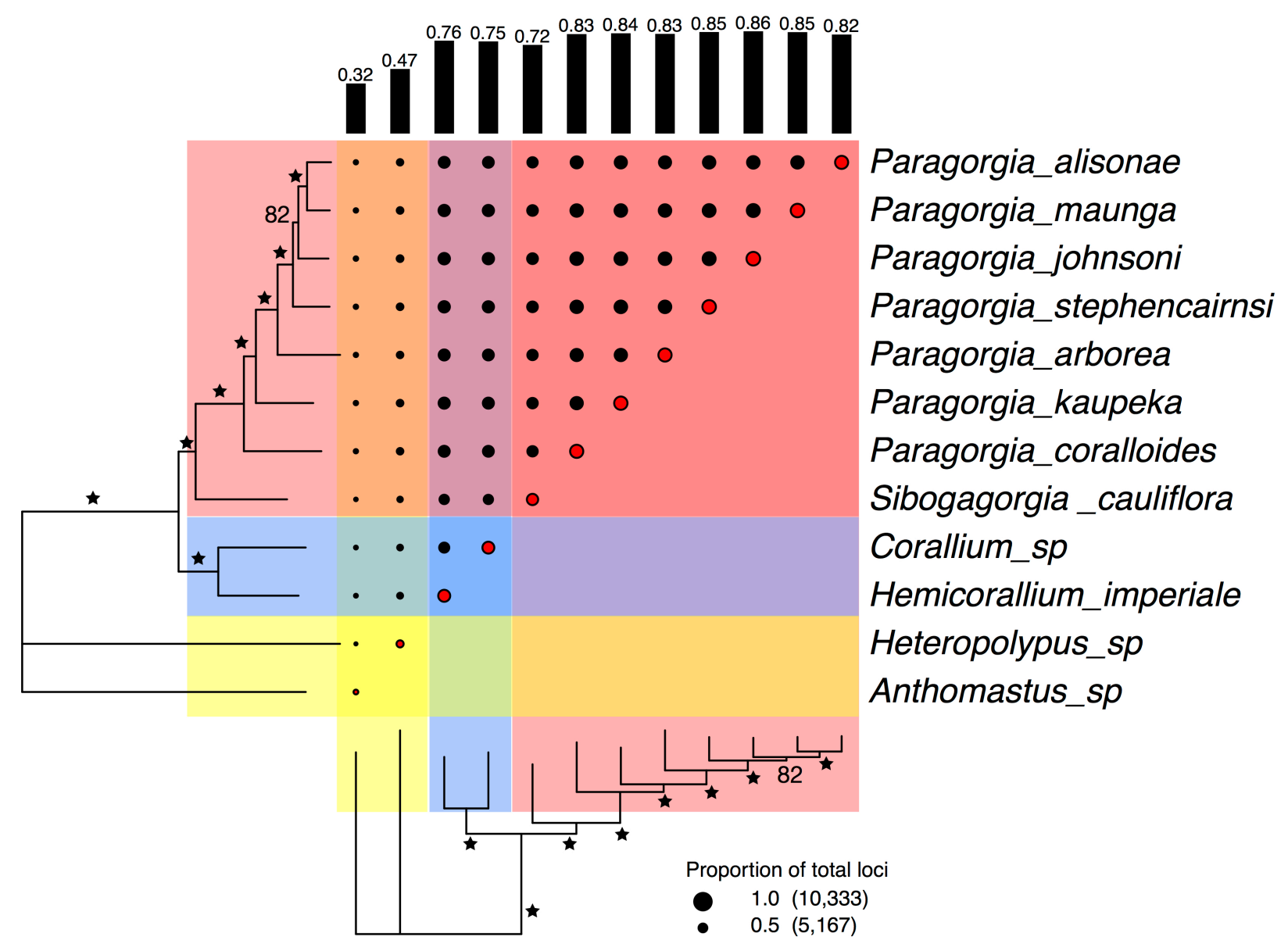

Figure 1. Proportion of loci shared among individuals of the AC clade in the optimal backbone matrix (c $0.80, \mathrm{~m}$ 9). Each family is indicated with a different color: red for Paragorgiidae; blue for Coralliidae; and yellow for Alcyoniidae. Black-filled circles represent the proportion of the total number of loci shared among individuals. Redfilled circles represent the proportion of the total number of loci present in each individual. Circle scale shows the number of loci represented by 1.0 and 0.5 circle sizes. Black vertical bars represent the average proportion of loci shared by each individual. Phylogenetic tree was inferred with RAxML. Stars on the tree represent branch bootstrap support of 100. Smaller bootstrap support values are indicated with numbers. This figure was generated with the package RADami (Hipp et al. 2014). 


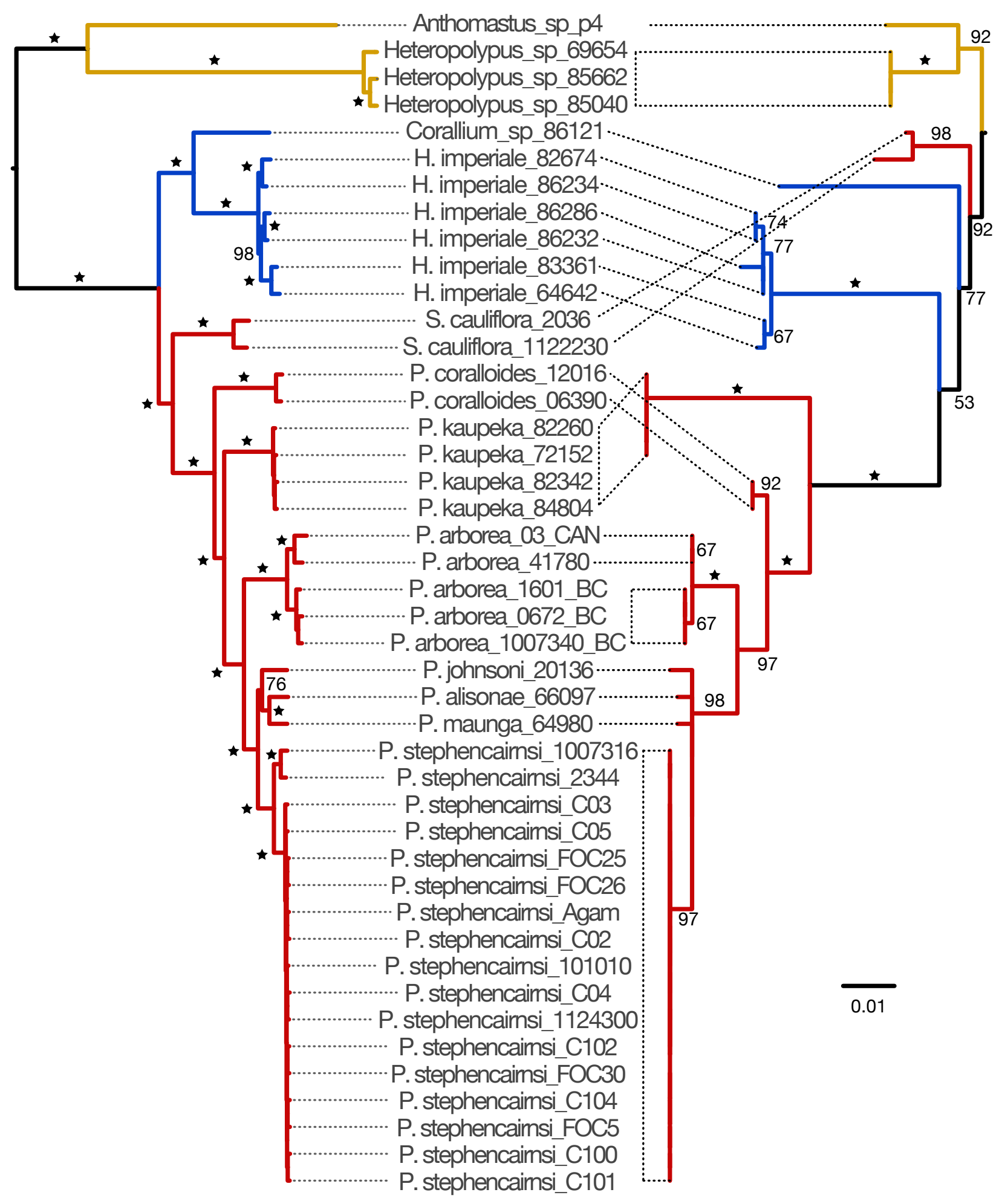

Figure 2. Phylogenetic trees of the $\mathrm{AC}$ clade based on RAD-seq and mitochondrial data. Left tree based on the RAD-seq concatenated PHYLO matrix. Right tree based on the mtMutS mitochondrial matrix. Each family is indicated with a different branch color: blue red for Paragorgiidaea; blue for Coralliidae; and yellow for Alcyoniidae. Phylogenetic trees were inferred with RAxML. Stars on the trees represent bootstrap support of 100. Smaller bootstrap values are indicated in numbers. Scale bar indicates substitutions per site. 


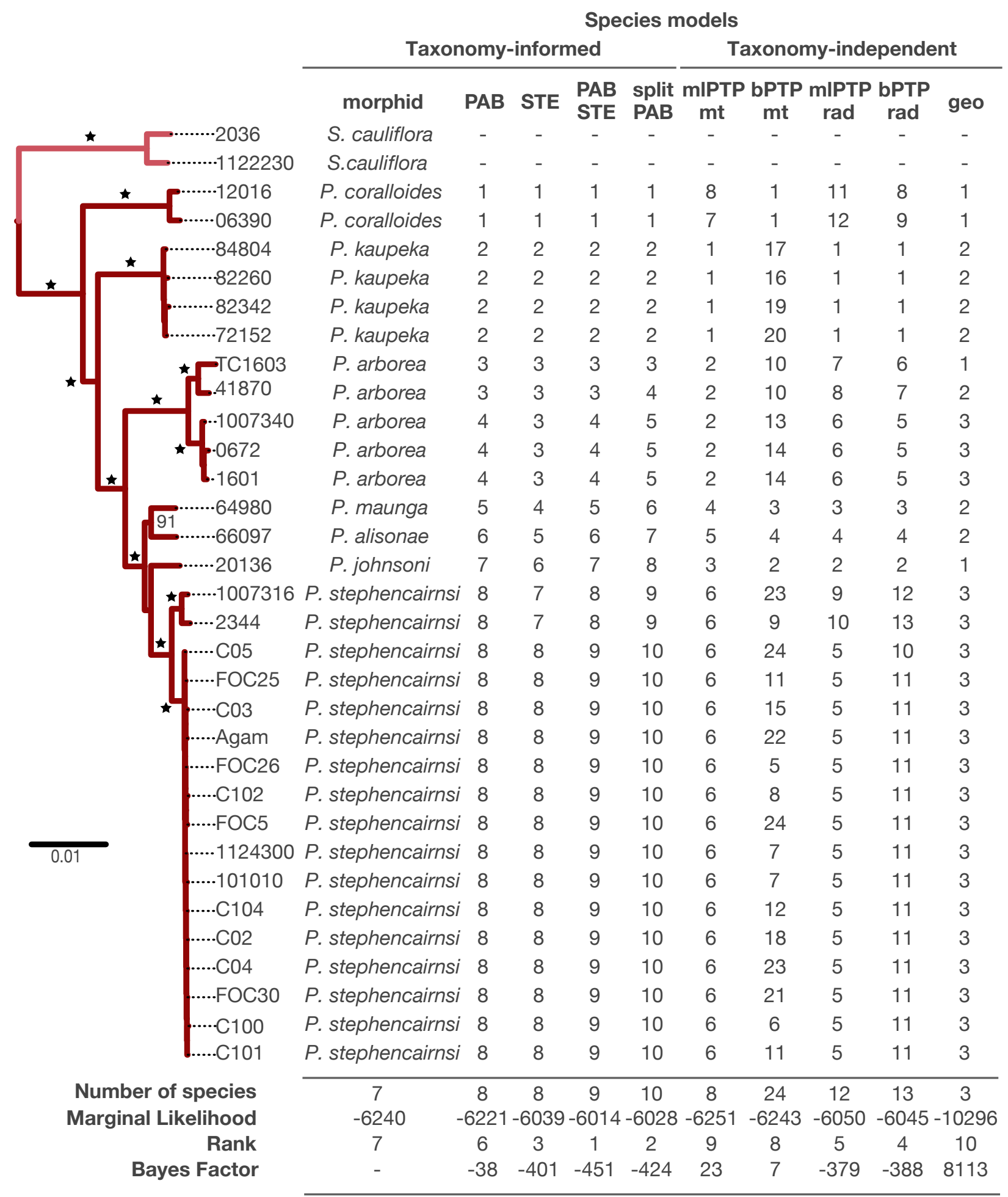

Figure 3. Species delineation hypotheses for Paragorgia. Table shows the different species delimitation models for Paragorgia evaluated with the BFD* method and their results. Sibogagorgia was included as outgroup to root the inferences for Paragorgia. Each row indicates a different specimen. Each column indicates a different species delimitation model. The first column, model morphid, indicates the species identifications based on morphology. 
For all other models, numbers indicate the species assignments. Bottom rows show the total number of species proposed, the marginal likelihood estimate, and rank for each model. The Bayes factor comparisons were calculated with respect to the null morphid model. Phylogenetic tree on the left, shown only for visual reference, was inferred with the RAD-seq concatenated PARAGORGIID matrix in RAxML. Each genus is indicated with a different branch color: pink for Sibogagorgia; and dark red for Paragorgia. Stars on the trees represent bootstrap support of 100. Smaller bootstrap values are indicated in numbers. Scale bar indicates substitutions per site.

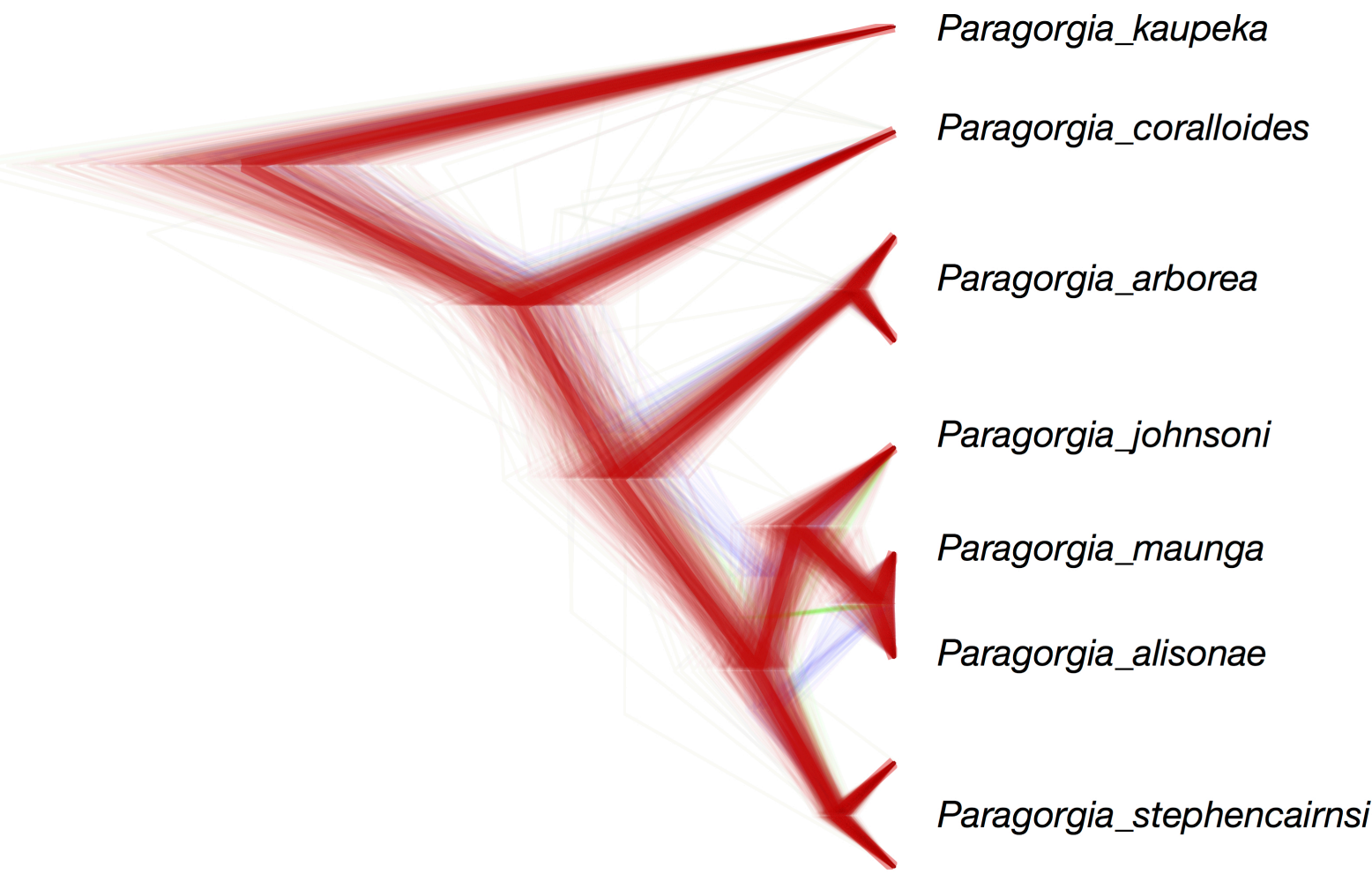

Figure 4. Species tree of Paragorgia. This claudogram illustrates the posterior distribution of species trees inferred with SNAPP based on the best species delimitation model PABSTE. High color density is indicative of areas in the species trees with high topology agreement. Different colors represent different topologies. The maximum clade credibility species tree is shown with thicker branches. Trees with the same topology as the maximum clade credibility species tree are colored in red. Trees with different topologies are colored green or blue. With the exception of the branch leading to the clade of P. johnsoni, P. maunga, and P. alisonae, which has a posterior probability of 0.87 , all interior branches have posterior probabilities of 1.0 . 
bioRxiv preprint doi: https://doi.org/10.1101/019745; this version posted May 24, 2015. The copyright holder for this preprint (which was not certified by peer review) is the author/funder, who has granted bioRxiv a license to display the preprint in perpetuity. It is made available under aCC-BY-NC-ND 4.0 International license.

\section{SUPPLEMENTARY MATERIALS}

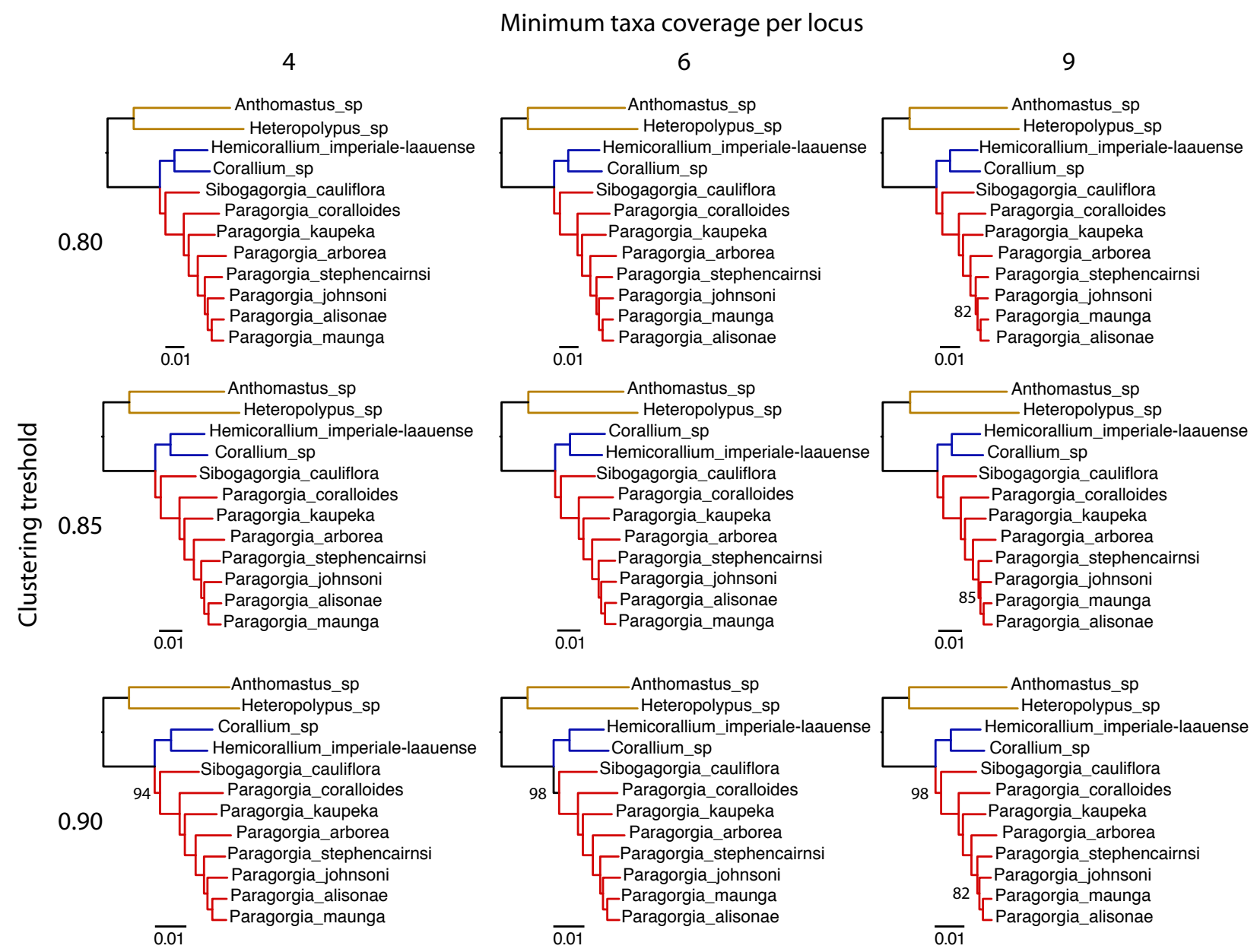

Figure S1. Phylogenetic trees based on backbone matrices. Trees inferred from the 9 backbone RAD-seq matrices built with different parameters of clustering threshold (c $0.80,0.85$ and 0.90 ; indicated by vertical labels) and

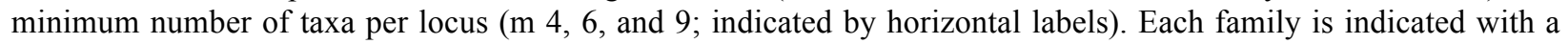
different branch color: red for Paragorgiidae; blue for Coralliidae; and yellow for Alcyoniidae. Trees were inferred with RAxML. All interior branches have bootstrap support values of 100, except for those shown. Scale bars indicate substitutions per site. 
bioRxiv preprint doi: https://doi.org/10.1101/019745; this version posted May 24, 2015. The copyright holder for this preprint (which was not certified by peer review) is the author/funder, who has granted bioRxiv a license to display the preprint in perpetuity. It is made available under aCC-BY-NC-ND 4.0 International license.

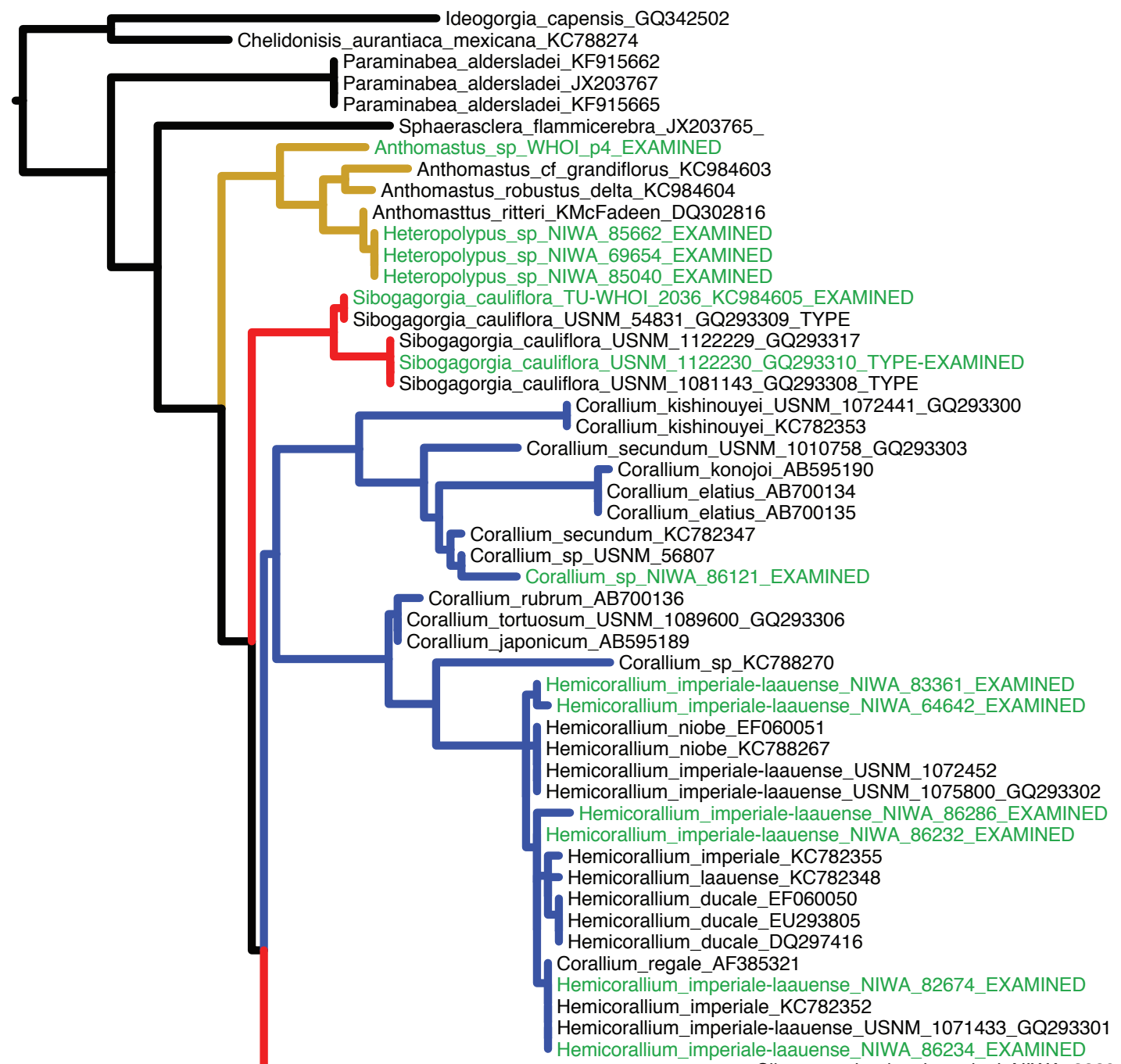

Sibogagorgia_dennisgordoni_NIWA_3329_GQ293316_TYPE

Paragorgia kaupeka NIWA 82260 EXAMINED

Paragorgia_kaupeka_NIWA_72152_EXAMINED

Paragorgia_kaupeka_NIWA_3320_GQ293313_TYPE

Paragorgia_kaupeka_NIWA_82342_EXAMINED

Paragorgia kaupeka NIWA 84804 EXAMINED

Paragorgia_sp_NIWA_28423

Paragorgia_sp_USNM_1075751

Paragorgia_sp_USNM 1075750

Paragorgia_sp_USNM_1075757

Paragorgia_regalis_USNM_1072339

Paragorgia_sp_USNM_1075759

Paragorgia coralloides WHOI 12016 EXAMINED

Paragorgia_sp_USNM_1072336

Paragorgia_sp_USNM_1075755

Paragorgia_cf_dendroides_USNM_1122228

Paragorgia_sp_NIWA 32830

Paragorgia_sp_USNM_1007354

Paragorgia_Sp_USNM_1082595

Paragorgia_coralloides_WHOI 06390 EXAMINED

Paragorgia_sp_USNM_1075756

Paragorgia_sp_YPM_28946

Paragorgia_sp_YPM_28911

Paragorgia regalis USNM 1072340

Paragorgia_sp_YPM_28921

Paragorgia_sp_NIWA_41849

Paragorgia_regalis_USNM_1122192

Paragorgia_sp_USNM_1082600

Paragorgia_sp_USNM_1075769

Paragorgia_coralloides_USNM_98785_JX128350

Paragorgia_sp_YPM_28717

Paragorgia_sp_YPM_37148 
bioRxiv preprint doi: https://doi.org/10.1101/019745; this version posted May 24, 2015. The copyright holder for this preprint (which was not certified by peer review) is the author/funder, who has granted bioRxiv a license to display the preprint in perpetuity. It is made available under aCC-BY-NC-ND 4.0 International license.

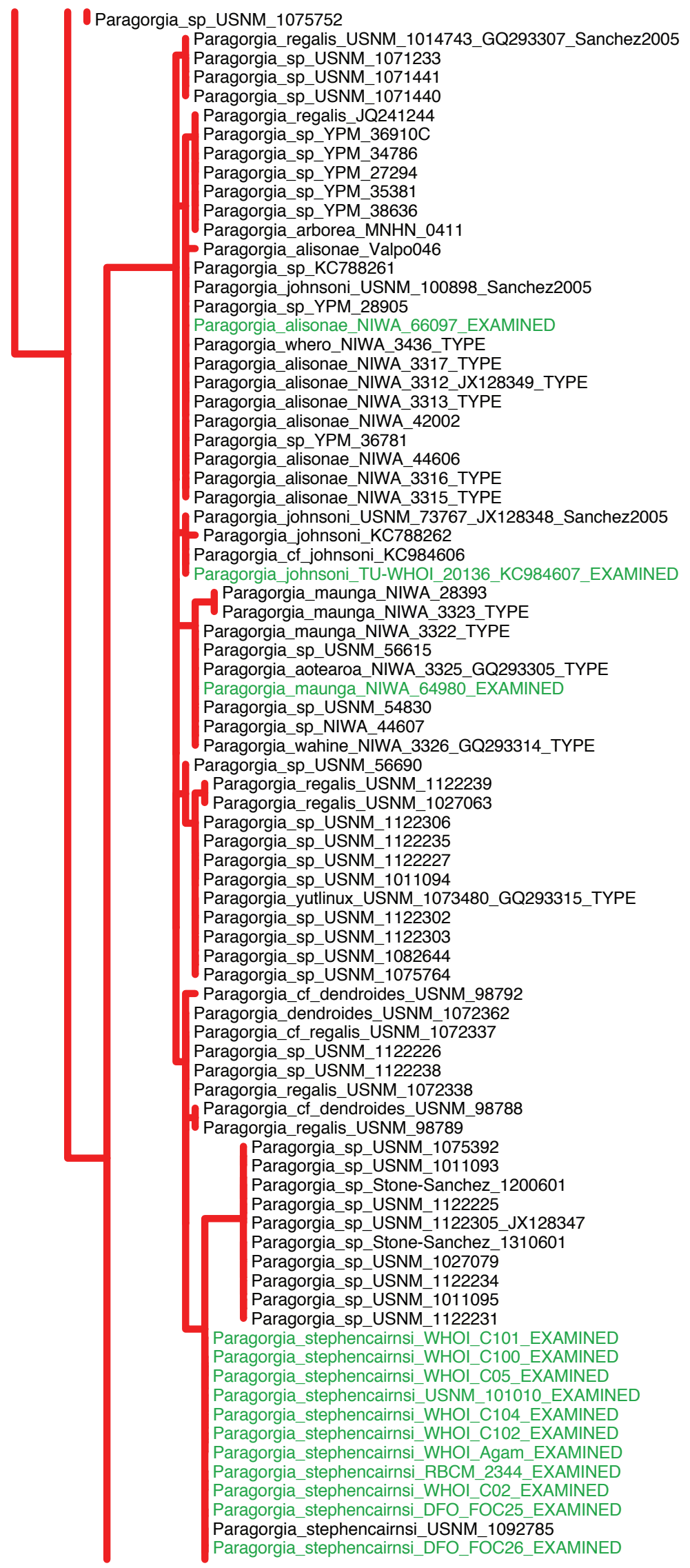


bioRxiv preprint doi: https://doi.org/10.1101/019745; this version posted May 24, 2015. The copyright holder for this preprint (which was not certified by peer review) is the author/funder, who has granted bioRxiv a license to display the preprint in perpetuity. It is made available under aCC-BY-NC-ND 4.0 International license.

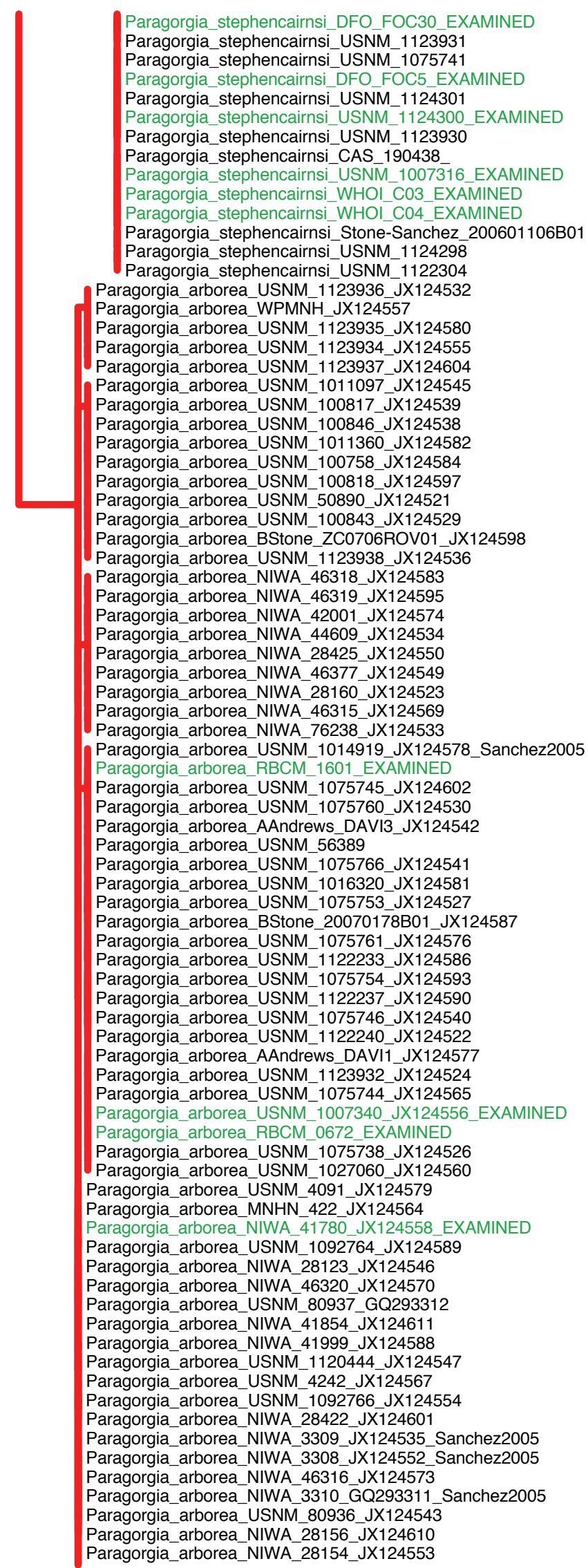


bioRxiv preprint doi: https://doi.org/10.1101/019745; this version posted May 24, 2015. The copyright holder for this preprint (which was not certified by peer review) is the author/funder, who has granted bioRxiv a license to display the preprint in perpetuity. It is made available under aCC-BY-NC-ND 4.0 International license.

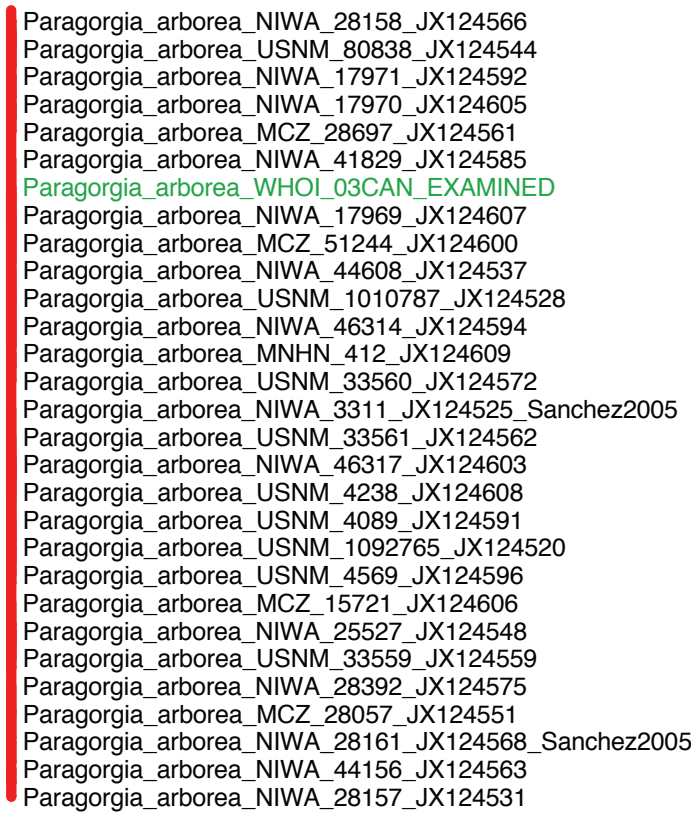

0.02

Figure S2. Mitochondrial $m t M u t S$ gene tree of all available sequences for the clade AC. Tree inferred from $m t M u t S$ sequence data from specimens examined in this study, GenBank, and additional specimens. Each family is indicated with a different branch color: red for Paragorgiidae; blue for Coralliidae; and yellow for Alcyoniidae. Outgroups are indicated with black branches. Specimens examined in detail in this study are indicated with green labels. Type specimens are labeled TYPE. Specimens examined in Sanchez (2005) are labeled "Sanchez2005". Tree was inferred with RAxML. Scale bars indicate substitutions per site. 
bioRxiv preprint doi: https://doi.org/10.1101/019745; this version posted May 24, 2015. The copyright holder for this preprint (which was not certified by peer review) is the author/funder, who has granted bioRxiv a license to display the preprint in perpetuity. It is made available under aCC-BY-NC-ND 4.0 International license.

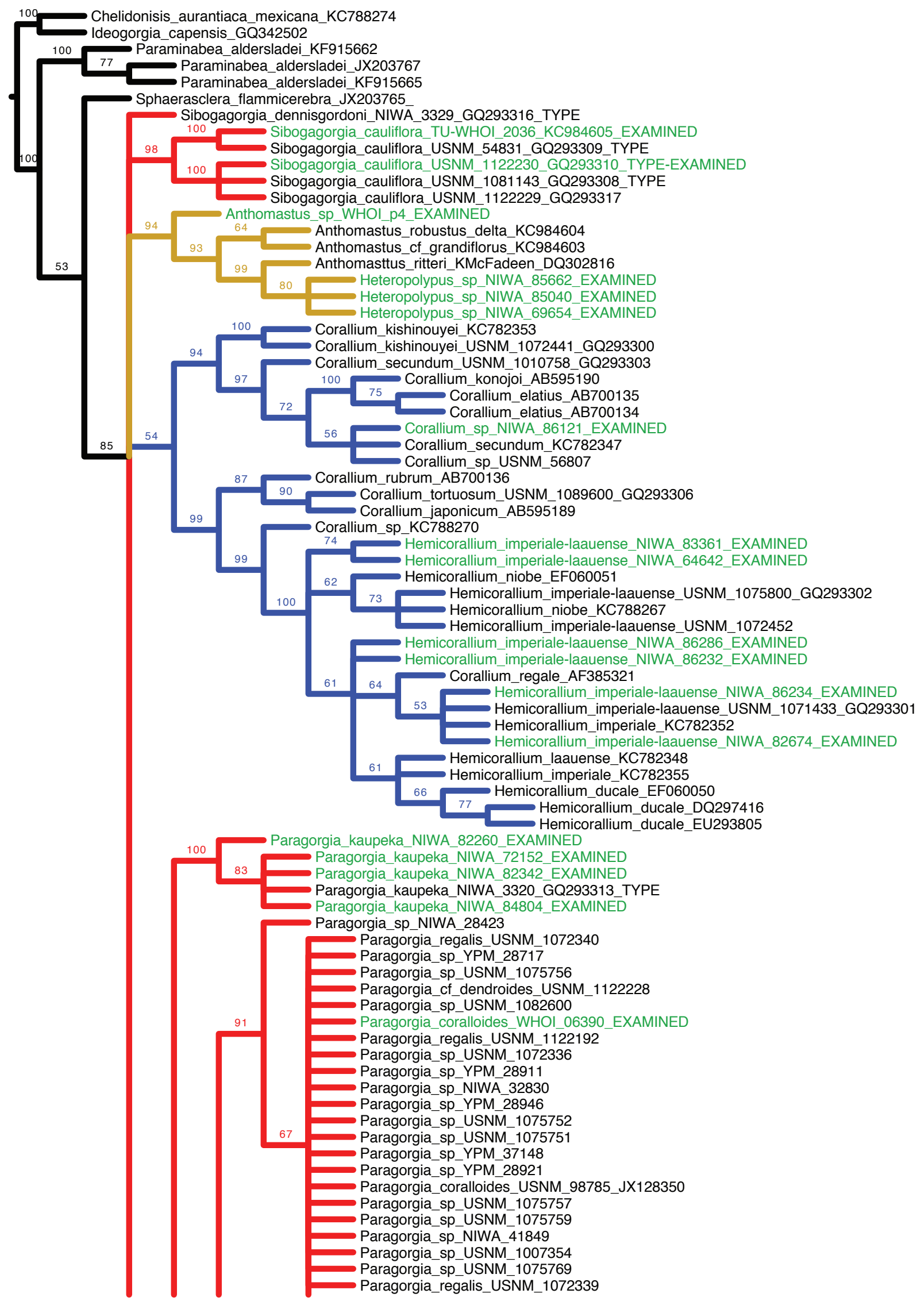


bioRxiv preprint doi: https://doi.org/10.1101/019745; this version posted May 24, 2015. The copyright holder for this preprint (which was not certified by peer review) is the author/funder, who has granted bioRxiv a license to display the preprint in perpetuity. It is made available under aCC-BY-NC-ND 4.0 International license.

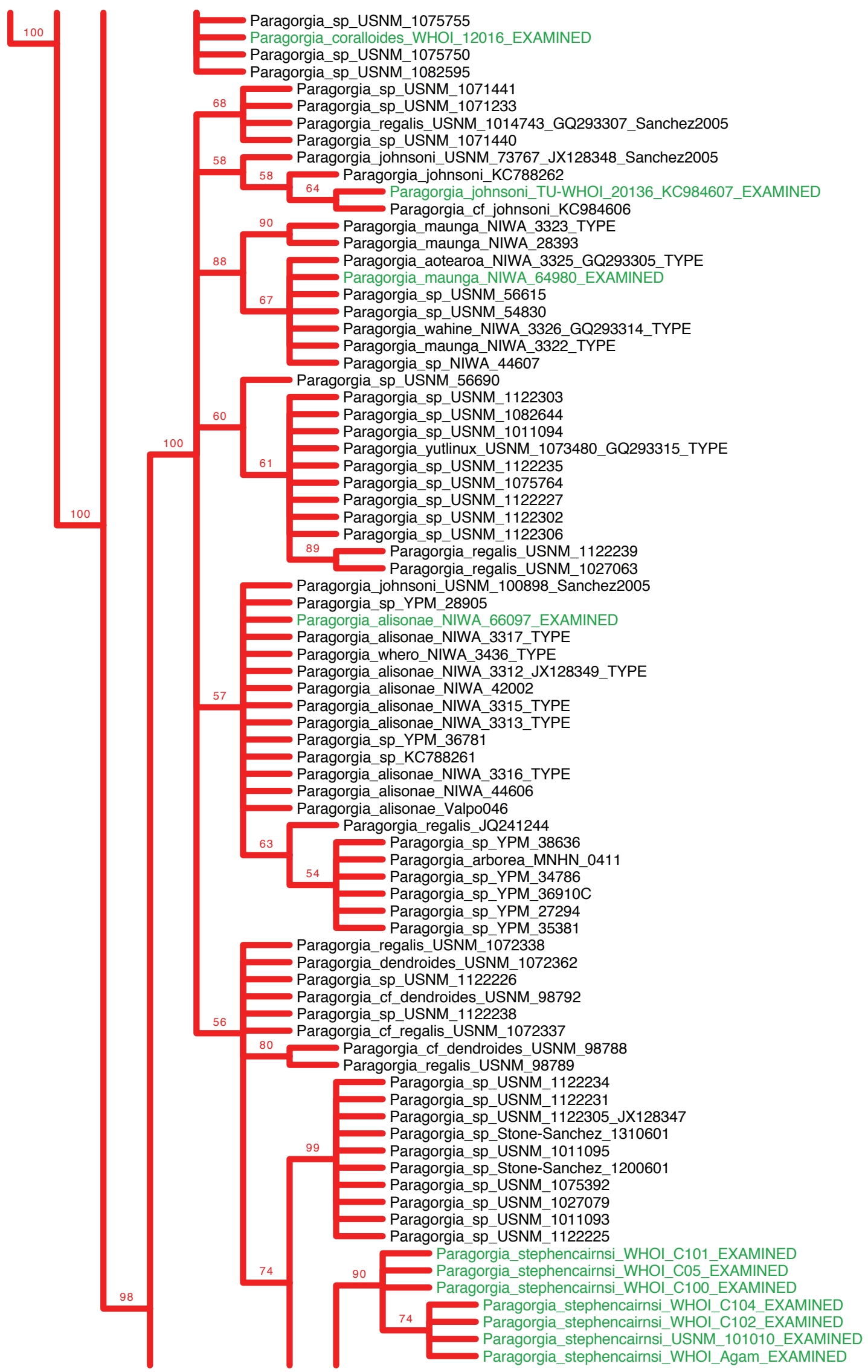


bioRxiv preprint doi: https://doi.org/10.1101/019745; this version posted May 24, 2015. The copyright holder for this preprint (which was not certified by peer review) is the author/funder, who has granted bioRxiv a license to display the preprint in perpetuity. It is made available under aCC-BY-NC-ND 4.0 International license.

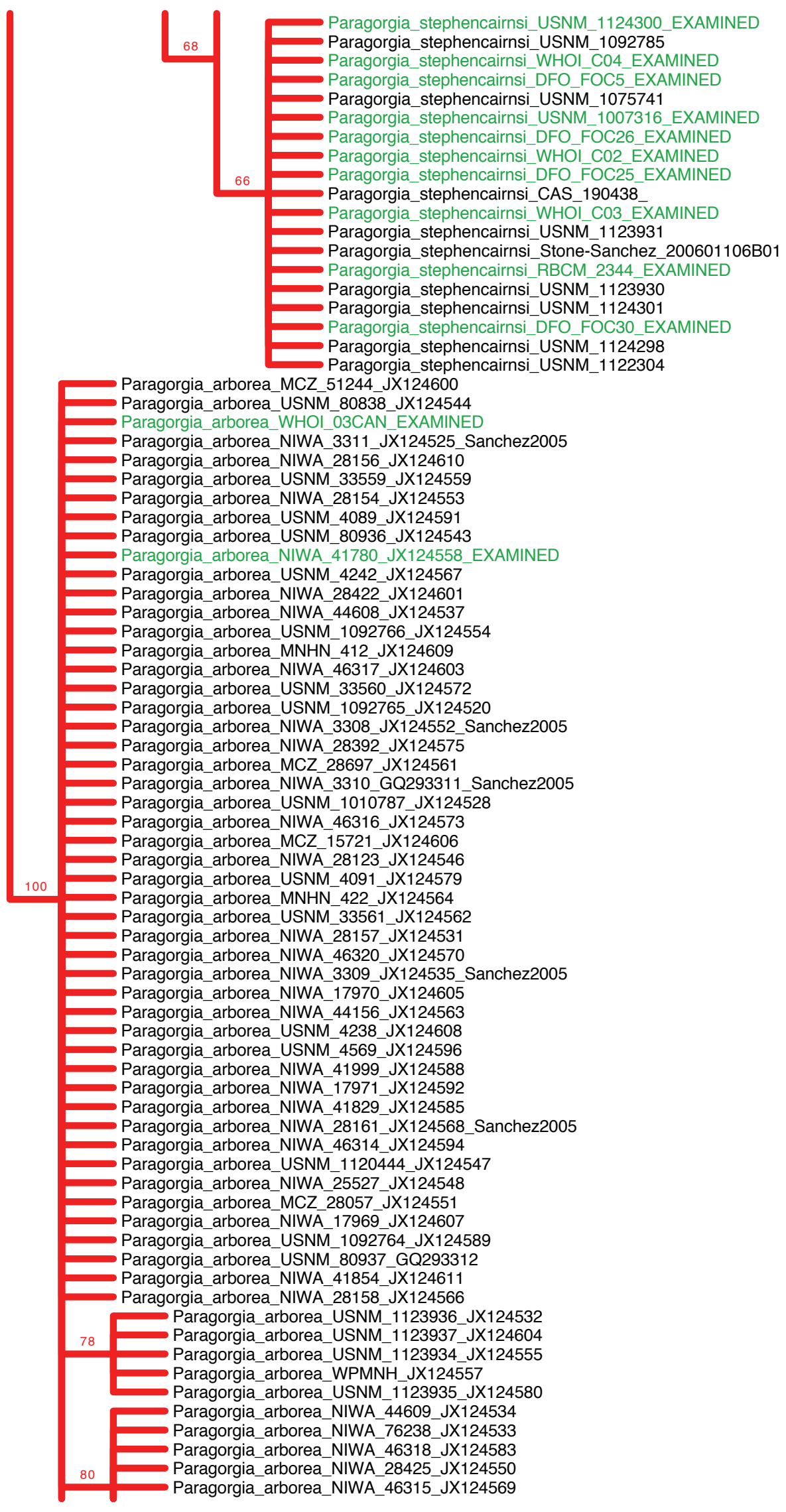


bioRxiv preprint doi: https://doi.org/10.1101/019745; this version posted May 24, 2015. The copyright holder for this preprint (which was not certified by peer review) is the author/funder, who has granted bioRxiv a license to display the preprint in perpetuity. It is made available under aCC-BY-NC-ND 4.0 International license.

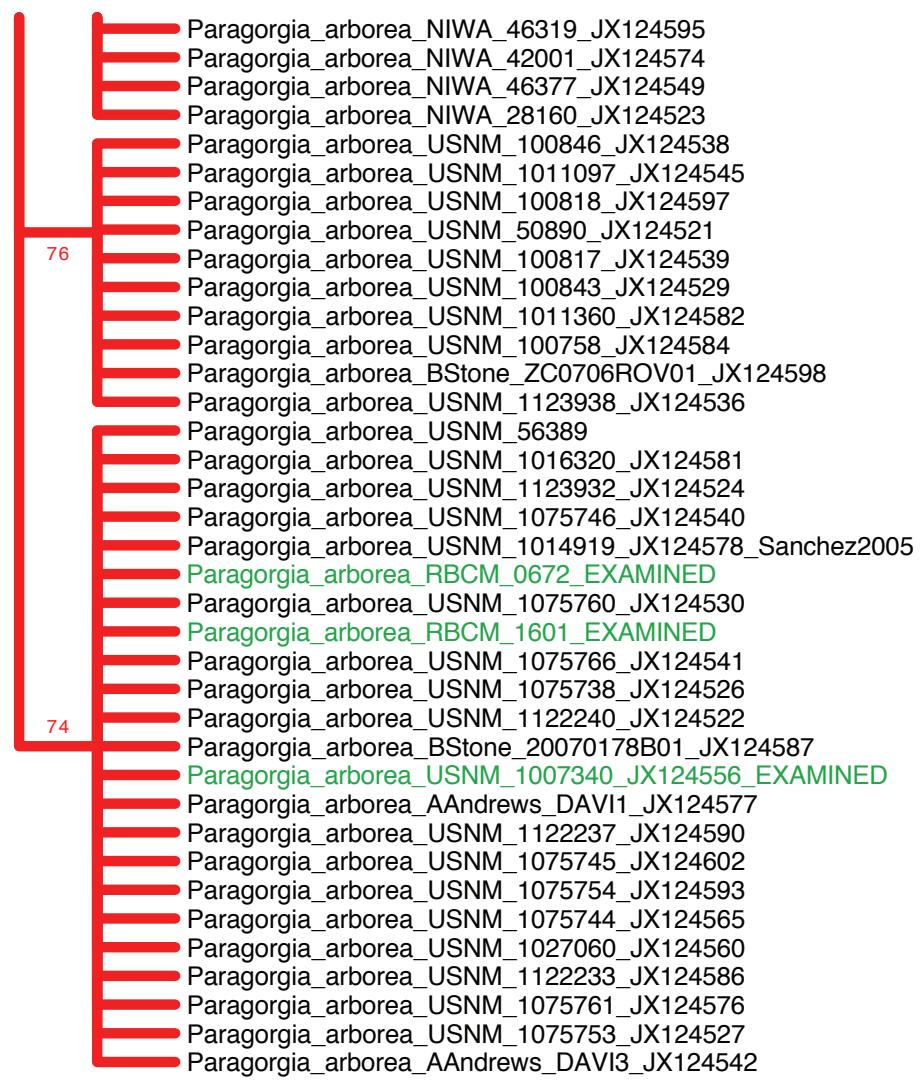

Figure S3. Mitochondrial $m t M u t S$ bootstrap support consensus tree of all available sequences for the clade AC. Tree inferred from $m t M u t S$ sequence data from specimens examined in this study, GenBank, and additional specimens. Each family is indicated with a different branch color: red for Paragorgiidae; blue for Coralliidae; and yellow for Alcyoniidae. Outgroups are indicated with black branches. Specimens examined in detail in this study are indicated with green labels. Type specimens are labeled "TYPE". Specimens examined in Sanchez (2005) are labeled "Sanchez2005". Tree was created with RAxML using a 50\% majority consensus from 500 bootstrap replicates. 
bioRxiv preprint doi: https://doi.org/10.1101/019745; this version posted May 24, 2015. The copyright holder for this preprint (which was not

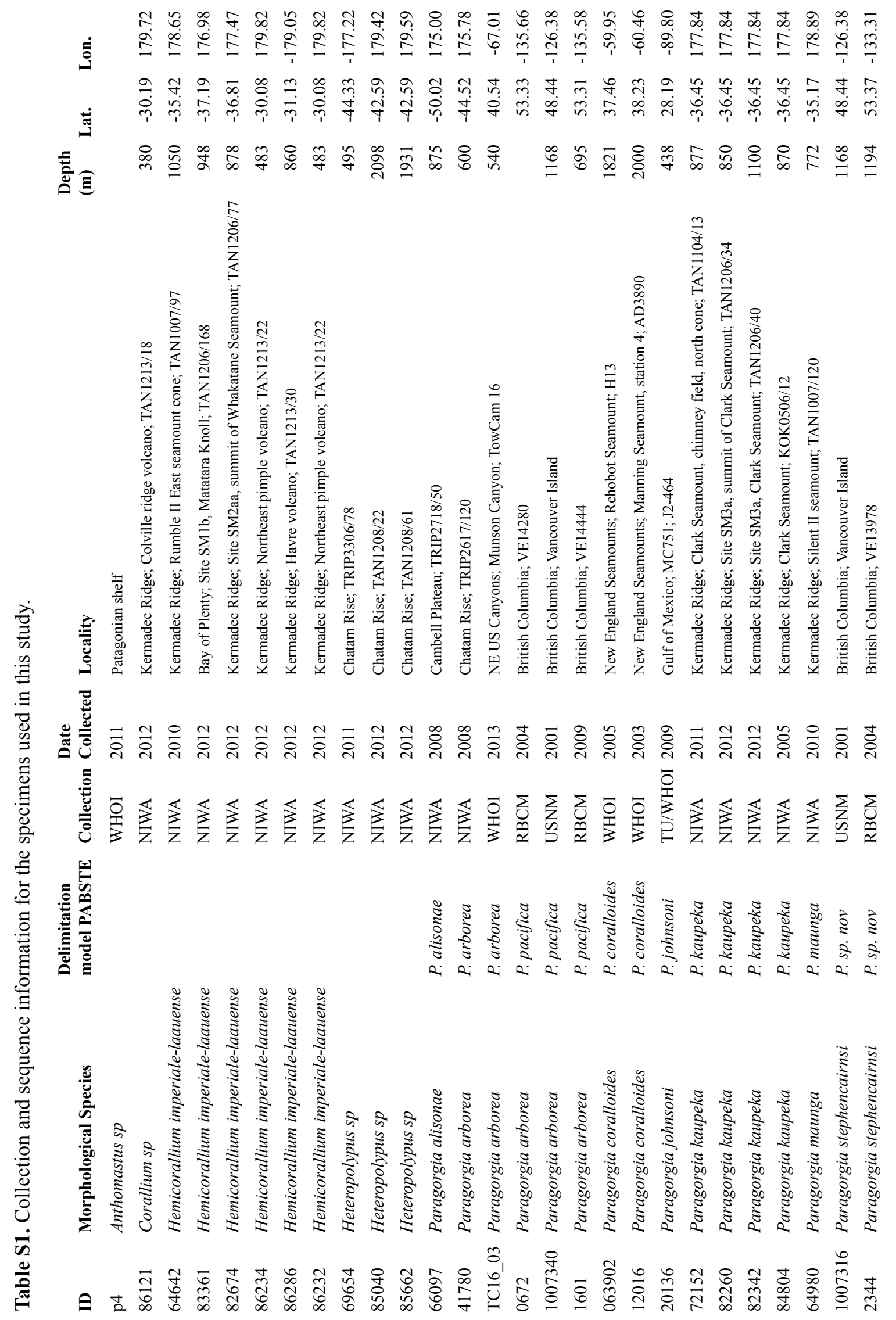


f. $\rightarrow$ है

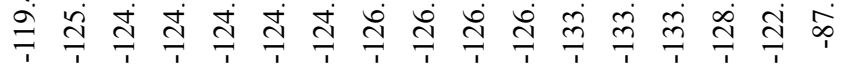

๙

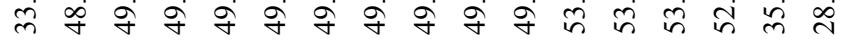

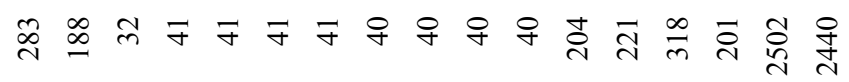

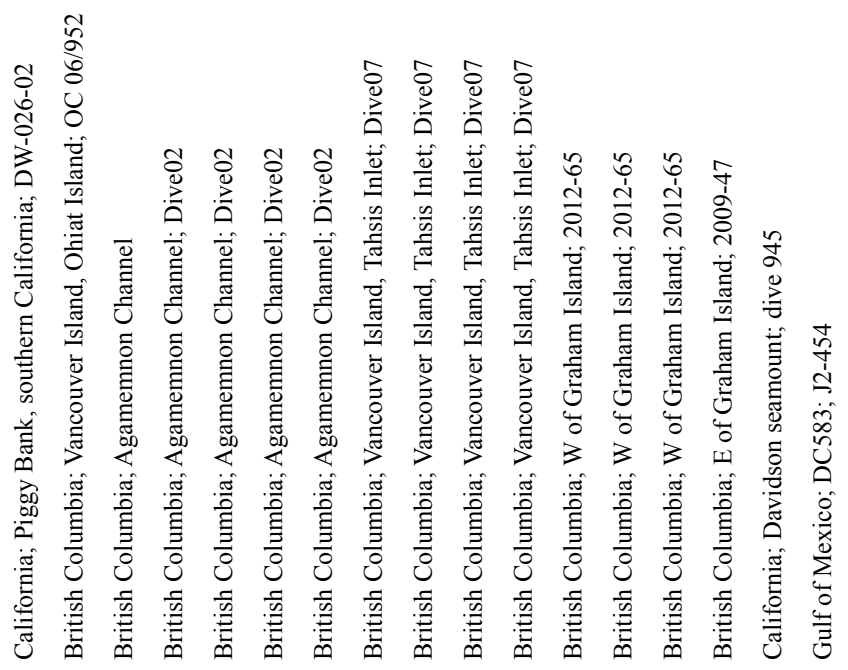

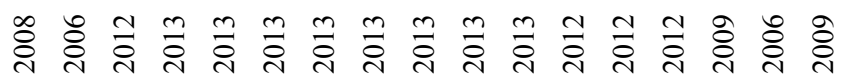

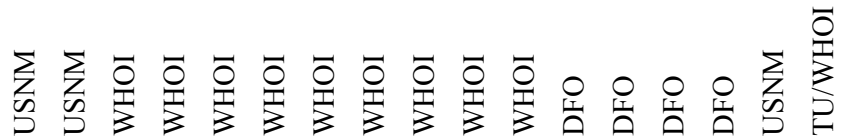

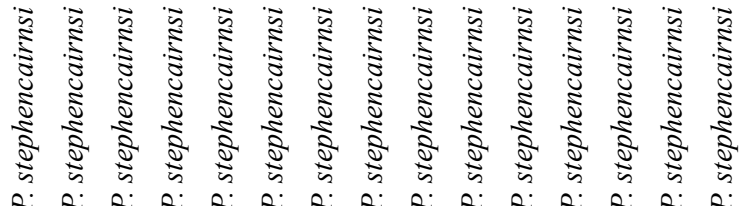

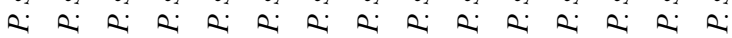

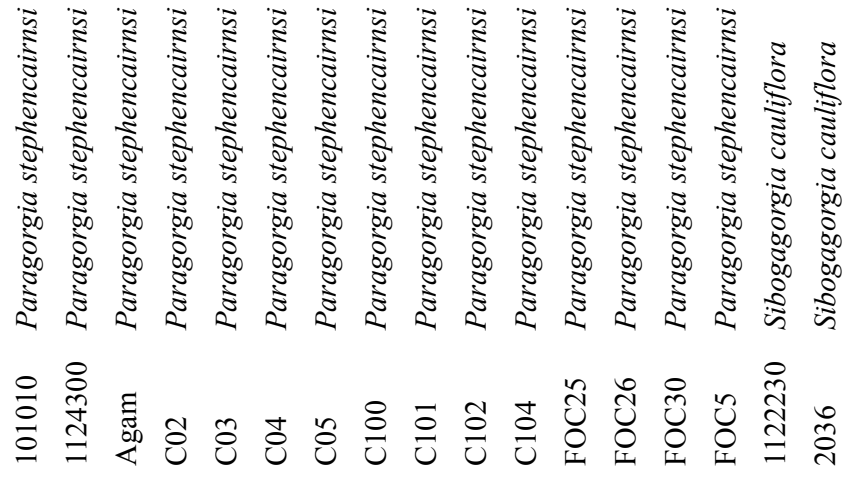


Table S2. RAD sequencing results and filtering statistics.

\begin{tabular}{|c|c|c|c|c|c|c|c|c|c|}
\hline & & & & STACKS & $S$ filtering & & RAD filter & ring & \\
\hline $\begin{array}{l}\text { Morphological } \\
\text { Species }\end{array}$ & $\begin{array}{l}\text { Delimitation } \\
\text { model PABSTE }\end{array}$ & $\begin{array}{l}\text { RAD-seq data file } \\
\text { ID }\end{array}$ & $\begin{array}{l}\text { Total } \\
\text { sequenced } \\
\text { reads }\end{array}$ & $\begin{array}{l}\text { Reads } \\
\text { discarded } \\
\text { due to low } \\
\text { quality }\end{array}$ & $\begin{array}{l}\text { Retained } \\
\text { reads }\end{array}$ & $\begin{array}{l}\text { Reads } \\
\text { that } \\
\text { passed } \\
\text { quality } \\
\text { filtering }\end{array}$ & $\begin{array}{l}\text { Trimmed } \\
\text { reads due } \\
\text { to } \\
\text { detection } \\
\text { of } \\
\text { adapters }\end{array}$ & $\begin{array}{l}\text { Total } \\
\text { number } \\
\text { of } \\
\text { retained } \\
\text { reads }\end{array}$ & $\begin{array}{l}\% \text { of } \\
\text { retained } \\
\text { reads } \\
\text { after } \\
\text { filtering } \\
\text { steps }\end{array}$ \\
\hline Anthomastus sp & & PoC_p4_ARG & $2,207,834$ & 151,391 & $1,312,903$ & $1,076,607$ & 38,570 & $1,115,177$ & 50.51 \\
\hline Corallium $s p$ & & COR_86121_NZ & $3,826,317$ & 305,019 & $3,013,324$ & $2,555,644$ & 22,650 & $2,578,294$ & 67.38 \\
\hline H. imperiale-laaue & inse & COR_64642_NZ & $4,344,702$ & 239,625 & $4,105,077$ & $3,697,256$ & 21,823 & $3,719,079$ & 85.60 \\
\hline H. imperiale-laaue & inse & COR_83361_NZ & $3,351,944$ & 291,963 & $2,588,492$ & $2,103,039$ & 37,016 & $2,140,055$ & 63.85 \\
\hline H. imperiale-laaue & inse & HEM_82674_NZ & $4,455,288$ & 364,162 & $3,777,461$ & $3,216,577$ & 40,911 & $3,257,488$ & 73.12 \\
\hline H. imperiale-laaue & nse & HEM_86234_NZ & $2,408,325$ & 186,372 & $2,142,057$ & $1,876,187$ & 16,195 & $1,892,382$ & 78.58 \\
\hline H. imperiale-laaue & inse & HEM_86286_NZ & $5,324,532$ & 446,268 & $4,266,674$ & $3,577,980$ & 42,661 & $3,620,641$ & 68.00 \\
\hline H. imperiale-laaue & inse & PAR_86232_NZ & $6,092,276$ & 503,438 & $5,206,376$ & $4,454,042$ & 35,518 & $4,489,560$ & 73.69 \\
\hline Heteropolypus sp & & ANT_69654_NZ & $4,300,289$ & 349,226 & $3,645,814$ & $3,139,309$ & 32,395 & $3,171,704$ & 73.76 \\
\hline Heteropolypus sp & & ANT_85040_NZ & $4,498,336$ & 393,748 & $3,882,304$ & $3,333,172$ & 26,687 & $3,359,859$ & 74.69 \\
\hline Heteropolypus sp & & ANT_85662_NZ & $3,487,138$ & 283,856 & $2,812,750$ & $2,382,184$ & 40,135 & $2,422,319$ & 69.46 \\
\hline P. alisonae & P. alisonae & PAR_66097_NZ & $3,007,362$ & 220,209 & $2,511,717$ & $2,219,265$ & 21,207 & $2,240,472$ & 74.50 \\
\hline P. arborea & P. arborea & PAR_41780_NZ & $6,668,080$ & 367,144 & $6,300,936$ & $5,655,328$ & 33,758 & $5,689,086$ & 85.32 \\
\hline P. arborea & P. arborea & PAR_TC16_03_CAN & $2,259,880$ & 167,106 & $1,799,244$ & $1,556,363$ & 17,448 & $1,573,811$ & 69.64 \\
\hline P. arborea & P. pacifica & PAR_0672_BC & $4,348,226$ & 293,526 & $4,054,700$ & $3,543,642$ & 29,284 & $3,572,926$ & 82.17 \\
\hline P. arborea & P. pacifica & PAR_1007340_BCD & $2,808,882$ & 251,102 & $2,431,829$ & $2,063,940$ & 25,831 & $2,089,771$ & 74.40 \\
\hline P. arborea & P. pacifica & PAR_1601_BC & $4,202,185$ & 221,386 & $3,980,799$ & $3,606,334$ & 25,434 & $3,631,768$ & 86.43 \\
\hline P. coralloides & P. coralloides & PAR_063902_NES & $3,244,860$ & 185,122 & $3,059,738$ & $2,746,228$ & 20,408 & $2,766,636$ & 85.26 \\
\hline P. coralloides & P. coralloides & PAR_12016_NES & $3,838,375$ & 226,253 & $3,612,122$ & $3,255,440$ & 15,945 & $3,271,385$ & 85.23 \\
\hline P. johnsoni & P. johnsoni & PAR_20136_GOM & $7,751,624$ & 422,203 & $7,329,421$ & $6,623,446$ & 38,692 & $6,662,138$ & 85.95 \\
\hline P. kaupeka & P. kaupeka & PAR_72152_NZ & $3,909,139$ & 268,871 & $2,926,960$ & $2,531,796$ & 26,984 & $2,558,780$ & 65.46 \\
\hline P. kaupeka & P. kaupeka & PAR_82260_NZ & $5,511,873$ & 475,292 & $4,558,291$ & $3,824,683$ & 42,782 & $3,867,465$ & 70.17 \\
\hline P. kaupeka & P. kaupeka & PAR_82342_NZ & $4,056,319$ & 307,425 & $3,339,653$ & $2,866,786$ & 33,020 & $2,899,806$ & 71.49 \\
\hline P. kaupeka & P. kaupeka & PAR_84804_NZ & $2,828,879$ & 230,493 & $2,313,997$ & $1,968,495$ & 19,602 & $1,988,097$ & 70.28 \\
\hline P. maunga & P. maunga & PAR_11369_NZ & $2,536,311$ & 252,554 & $2,008,028$ & $1,619,915$ & 34,477 & $1,654,392$ & 65.23 \\
\hline P. stephencairnsi & P. sp. nov & PAR_1007316_BCD & $2,257,183$ & 151,729 & $1,606,180$ & $1,371,398$ & 36,692 & $1,408,090$ & 62.38 \\
\hline P. stephencairnsi & P. sp. nov & PAR_2344_BC & $2,858,311$ & 159,073 & $2,699,238$ & $2,414,787$ & 26,272 & $2,441,059$ & 85.40 \\
\hline P. stephencairnsi & P. stephencairnsi & $i$ PAR_101010_CA & $6,642,673$ & 398,317 & $6,244,356$ & $5,595,342$ & 39,240 & $5,634,582$ & 84.82 \\
\hline P. stephencairnsi & P. stephencairnsi & $i$ PAR_1124300_WA & $3,843,250$ & 215,859 & $3,627,391$ & $3,260,864$ & 27,921 & $3,288,785$ & 85.57 \\
\hline P. stephencairnsi & P. stephencairnsi & $i$ PAR_Agam_BC & $4,322,564$ & 260,095 & $4,062,469$ & $3,619,988$ & 26,669 & $3,646,657$ & 84.36 \\
\hline
\end{tabular}




\begin{tabular}{|c|c|c|c|c|c|c|c|c|c|}
\hline P. stephencairnsi & P. stephencairnsi & PAR_C02_BCS & $2,149,938$ & 153,978 & $1,594,818$ & $1,377,002$ & 16,157 & $1,393,159$ & 64.80 \\
\hline P. stephencairnsi & P. stephencairnsi & PAR_C03_BCS & $2,815,327$ & 245,051 & $2,264,951$ & $1,916,452$ & 19,800 & $1,936,252$ & 68.78 \\
\hline P. stephencairnsi & P. stephencairnsi & PAR_C04_BCS & $3,240,713$ & 267,042 & $2,754,373$ & $2,379,284$ & 22,261 & $2,401,545$ & 74.11 \\
\hline P. stephencairnsi & P. stephencairnsi & PAR_C05_BCS & $3,465,396$ & 294,547 & $2,972,548$ & $2,538,577$ & 25,005 & $2,563,582$ & 73.98 \\
\hline P. stephencairnsi & P. stephencairnsi & PAR_C100_BCS & $5,998,914$ & 480,465 & $4,984,766$ & $4,330,930$ & 38,445 & $4,369,375$ & 72.84 \\
\hline P. stephencairnsi & P. stephencairnsi & PAR_C101_BCS & $5,332,619$ & 446,452 & $4,652,535$ & $4,030,919$ & 30,684 & $4,061,603$ & 76.17 \\
\hline P. stephencairnsi & P. stephencairnsi & PAR_C102_BCS & $4,347,757$ & 348,662 & $3,710,381$ & $3,221,934$ & 26,559 & $3,248,493$ & 74.72 \\
\hline P. stephencairnsi & P. stephencairnsi & PAR_C104_BCS & $2,720,994$ & 210,479 & $2,203,568$ & $1,893,649$ & 19,213 & $1,912,862$ & 70.30 \\
\hline P. stephencairnsi & P. stephencairnsi & PAR_FOC25_BCD & $5,479,109$ & 453,625 & $4,693,804$ & $4,073,503$ & 34,583 & $4,108,086$ & 74.98 \\
\hline P. stephencairnsi & P. stephencairnsi & PAR_FOC26_BCD & $5,242,949$ & 477,361 & $4,528,629$ & $3,778,655$ & 37,137 & $3,815,792$ & 72.78 \\
\hline P. stephencairnsi & P. stephencairnsi & PAR_FOC30_BCD & $4,417,520$ & 337,501 & $3,781,973$ & $3,312,791$ & 32,621 & $3,345,412$ & 75.73 \\
\hline P. stephencairnsi & P. stephencairnsi & PAR_FOC5_BCD & $2,834,377$ & 239,051 & $2,455,041$ & $2,109,251$ & 23,444 & $2,132,695$ & 75.24 \\
\hline S. cauliflora & & SIB_1122230_DAV & $1,701,751$ & 123,755 & $1,220,077$ & $1,016,203$ & 26,104 & $1,042,307$ & 61.25 \\
\hline \multirow[t]{3}{*}{ S. cauliflora } & & SIB_2036_GOM & $2,638,533$ & 191,392 & $2,373,232$ & $2,077,092$ & 20,727 & $2,097,819$ & 79.51 \\
\hline & & AVERAGE & $3,944,974$ & 292,232 & $3,395,704$ & $2,950,279$ & 28,840 & $2,979,119$ & 74.27 \\
\hline & & STD DEV. & $1,392,573$ & 105,332 & $1,352,276$ & $1,219,146$ & 7,968 & $1,222,799$ & 8.09 \\
\hline
\end{tabular}




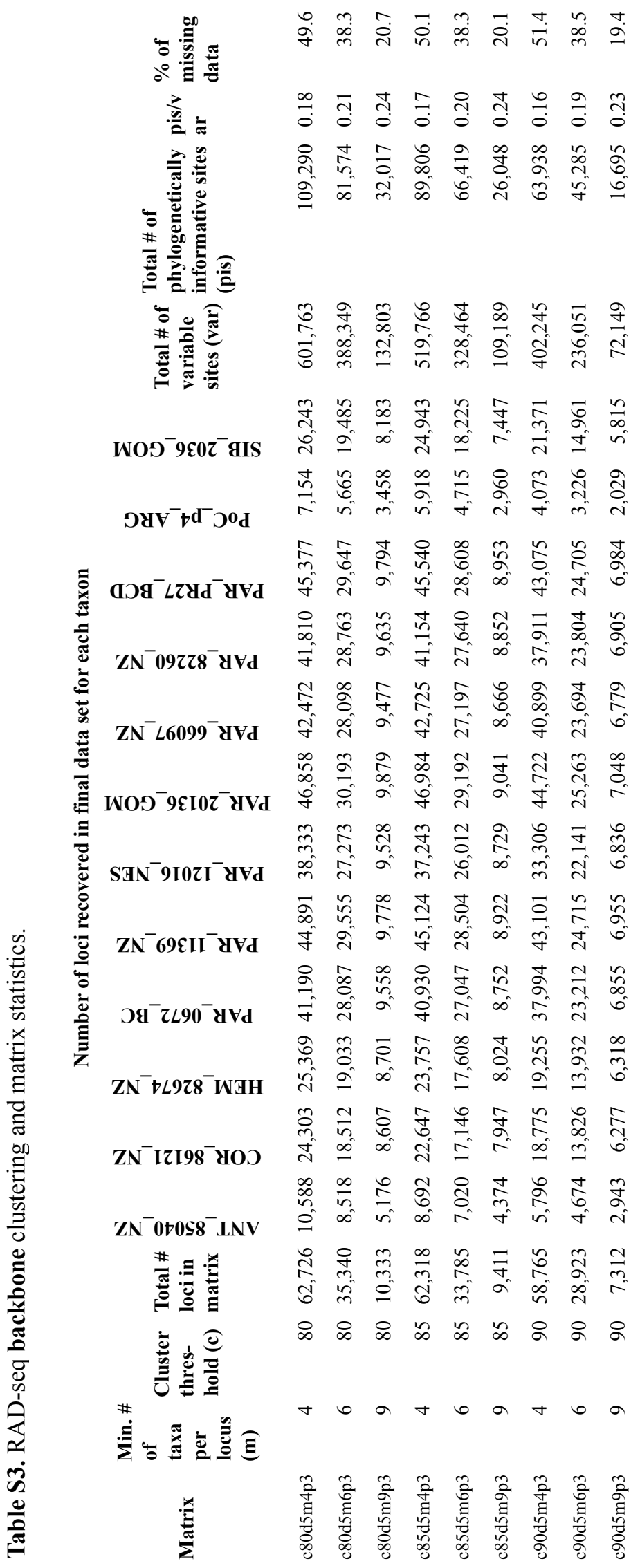


bioRxiv preprint doi: https://doi.org/10.1101/019745; this version posted May 24, 2015. The copyright holder for this preprint (which was not certified by peer review) is the author/funder, who has granted bioRxiv a license to display the preprint in perpetuity. It is made available under aCC-BY-NC-ND 4.0 International license.
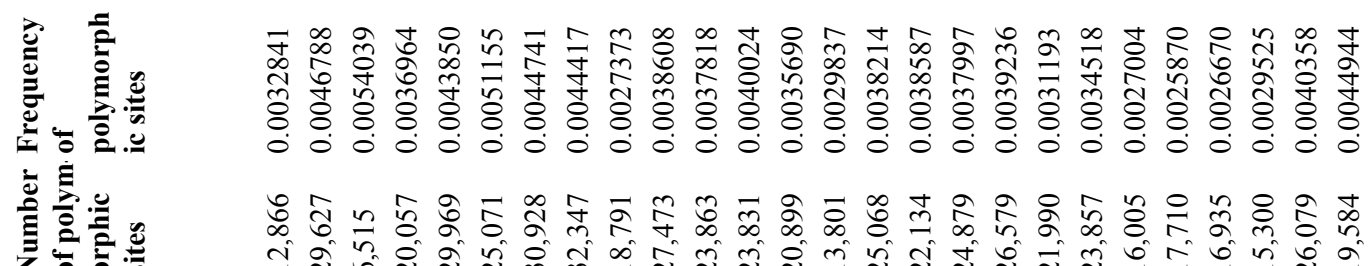

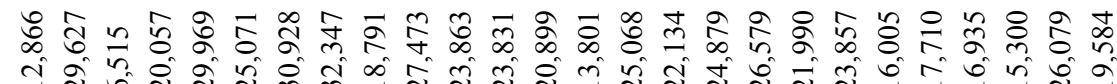

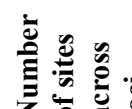

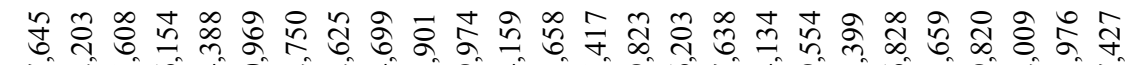

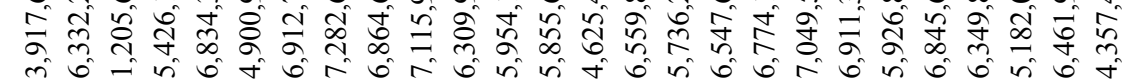

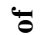

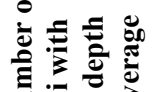

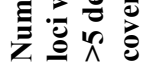

产兽

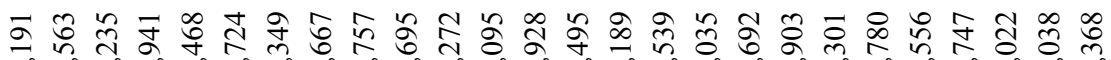

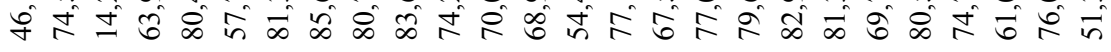

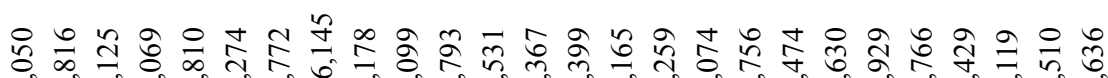

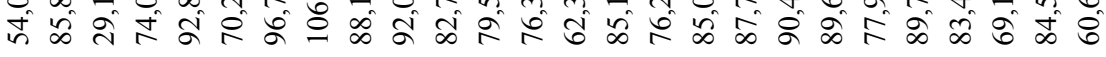

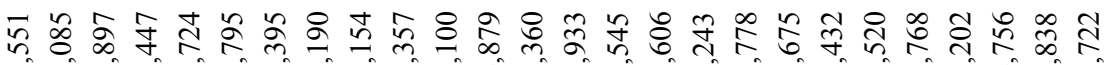
ป⿺尢丶

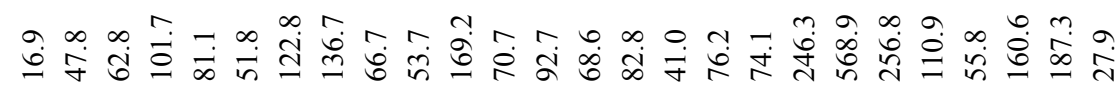

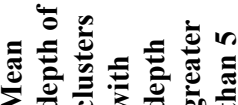

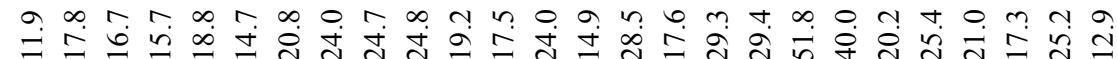

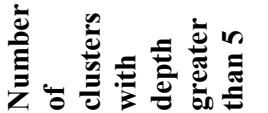

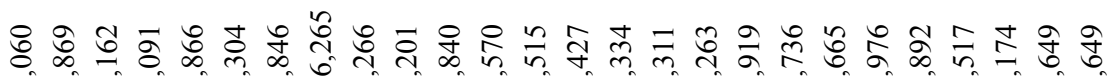

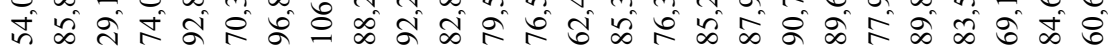

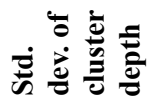

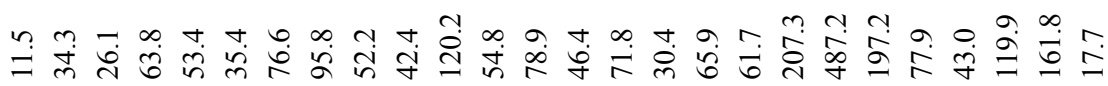

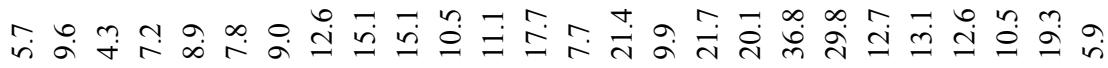

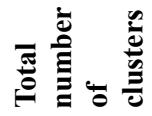

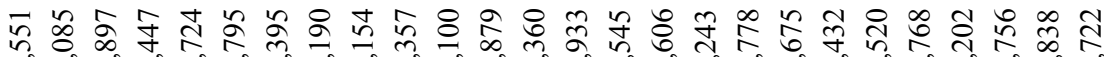

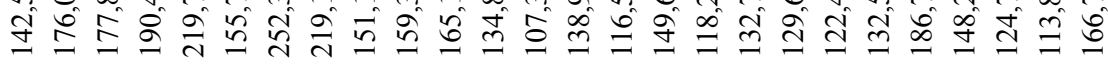

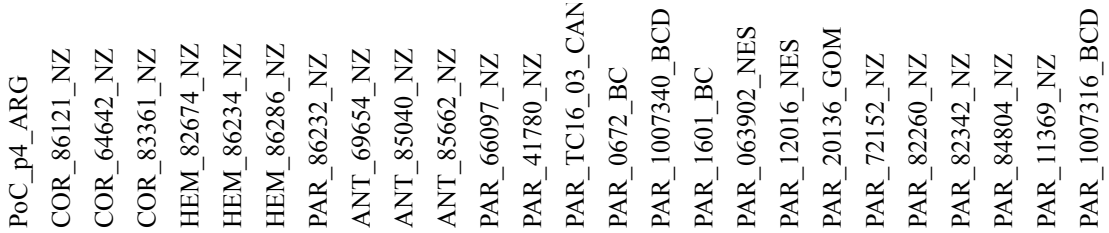


bioRxiv preprint doi: https://doi.org/10.1101/019745; this version posted May 24, 2015. The copyright holder for this preprint (which was not
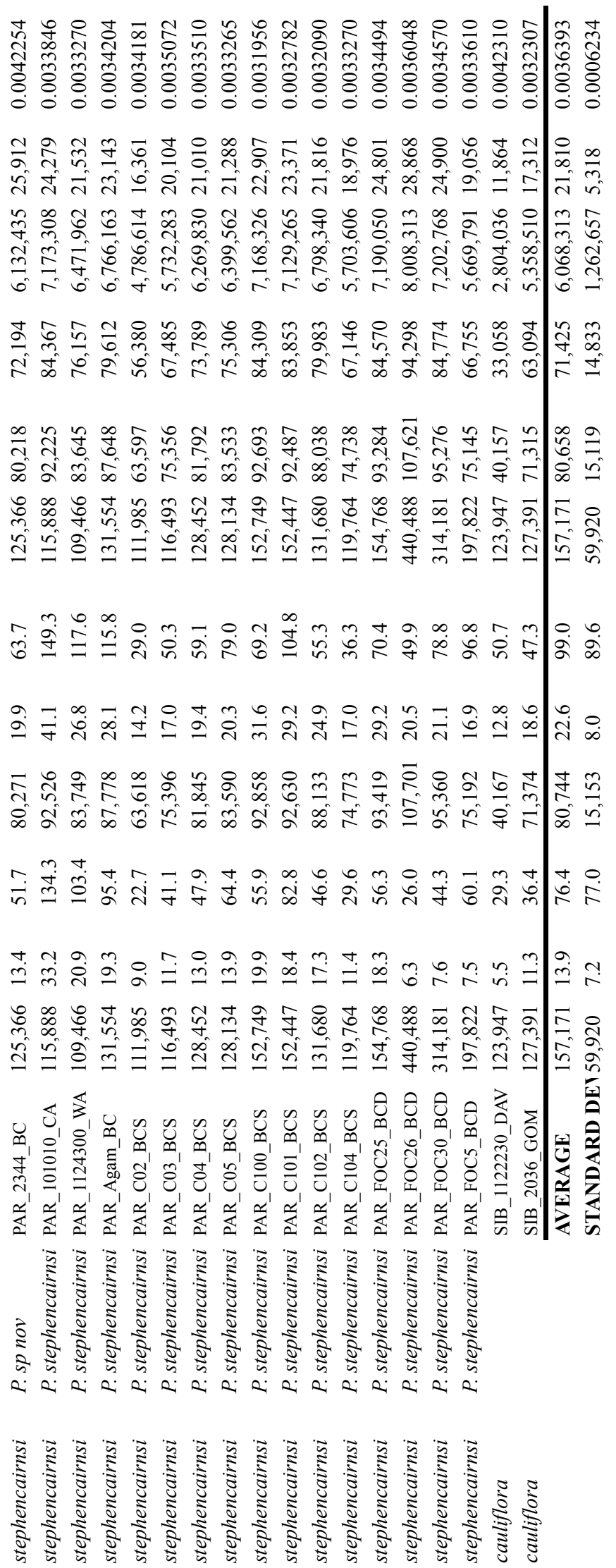
bioRxiv preprint doi: https://doi.org/10.1101/019745; this version posted May 24, 2015. The copyright holder for this preprint (which was not

Table S5. Nucleotide diversity and error rate estimates per specimen based on the PHYLO matrix

Morphological Species

Anthomastus sp

Corallium $s p$

H. imperiale-laauense*

H. imperiale-laauense

H. imperiale-laauense

H. imperiale-laauense

H. imperiale-laauense

$H$. imperiale-laauense

Heteropolypus $s p$

Heteropolypus $s p$

Heteropolypus $s p$

P. alisonae

P. arborea

P. arborea

P. arborea

P. arborea

P. arborea

P. coralloides

P. coralloides

P. johnsoni

P. kaupeka

P. kaupeka

P. kaupeka

P. kaupeka

P. maunga

P. stephencairnsi

P. stephencairnsi

P. stephencairnsi

P. stephencairnsi

P. stephencairnsi

P. stephencairnsi

P. stephencairnsi

P. stephencairnsi

P. stephencairnsi

P. stephencairnsi

P. stephencairnsi

P. stephencairnsi

P. stephencairnsi

P. stephencairnsi

P. stephencairnsi

P. stephencairnsi

P. stephencairnsi

S. cauliflora

S. cauliflora
PABSTE

P. alisonae

P. arborea

P. arborea

P. pacifica

P. pacifica

P. pacifica

P. coralloides

P. coralloides

P. johnsoni

P. kaupeka

P. kaupeka

P. kaupeka

P. kaupeka

P. maunga

P. sp. nov

P. sp. nov

P. stephencairnsi

P. stephencairnsi

P. stephencairnsi

P. stephencairnsi

P. stephencairnsi

P. stephencairnsi

P. stephencairnsi

P. stephencairnsi

P. stephencairnsi

P. stephencairnsi

P. stephencairnsi

P. stephencairnsi

P. stephencairnsi

P. stephencairnsi

P. stephencairnsi

*Excluded from calculations due to low number of loci

\section{RAD-seq data file ID}

PoC_p4_ARG

COR_86121_NZ

COR_64642_NZ

COR_83361_NZ

HEM_82674_NZ

HEM_86234_NZ

HEM_86286_NZ

PAR_86232_NZ

ANT_69654_NZ

ANT_85040_NZ

ANT_85662_NZ

PAR_66097_NZ

PAR_41780_NZ

PAR_TC16_03_CAN

PAR_0672_BC

PAR_1007340_BCD

PAR_1601_BC

PAR_063902_NES

PAR_12016_NES

PAR_20136_GOM

PAR_72152_NZ

PAR_82260_NZ

PAR_82342_NZ

PAR_84804_NZ

PAR_11369_NZ

PAR_1007316_BCD

PAR_2344_BC

PAR_101010_CA

PAR_1124300_WA

PAR_Agam_BC

PAR_C02_BCS

PAR_C03_BCS

PAR_C04_BCS

PAR_C05_BCS

PAR_C100_BCS

PAR_C101_BCS

PAR_C102_BCS

PAR_C104_BCS

PAR_FOC25_BCD

PAR_FOC26_BCD

PAR_FOC30_BCD

PAR_FOC5_BCD

SIB_1122230_DAV

SIB_2036_GOM

AVERAGE

SD

\section{Nucleotide diversity (Pi)}

0.01295412

0.01467291

0.04406216

0.01399387

0.01440962

0.01676557

0.01526906

0.01633107

0.00936378

0.01122064

0.01161827

0.0127996

0.01209999

0.01293451

0.01189447

0.01285038

0.01205019

0.01182997

0.01035726

0.01159218

0.01085919

0.01077562

0.01082052

0.01169178

0.01225252

0.01488811

0.01260347

0.01063818

0.01092481

0.01117934

0.01180863

0.01129071

0.01098867

0.01117442

0.01063313

0.0109634

0.01060609

0.01124495

0.01104859

0.01263196

0.01196811

0.0119129

0.01525699

0.01214983

0.01291599

0.00513429
Error Rate

0.0029032

0.00258843

0.01630744

0.00269528

0.00268885

0.00254558

0.00234296

0.00217237

0.00151989

0.00146665

0.00189506

0.00205016

0.00186767

0.00241858

0.00170062

0.00223148

0.00164477

0.00146894

0.00116583

0.00137491

0.00209157

0.00211998

0.00225821

0.00221668

0.00176518

0.00295065

0.00188425

0.00134692

0.00163497

0.00151902

0.00194975

0.00175198

0.00171446

0.00167389

0.00155401

0.00160305

0.00159815

0.00175065

0.00154584

0.00180015

0.00182162

0.00186229

0.00328691

0.00221517

0.00228532

0.00223806 
Table S6. Nucleotide diversity and error rate estimates per species based on the PHYLO matrix

\begin{tabular}{|c|c|c|c|c|c|c|c|}
\hline \multirow[b]{2}{*}{$\begin{array}{l}\text { Morphological } \\
\text { Species }\end{array}$} & \multirow[b]{2}{*}{$\begin{array}{l}\text { Delimitation } \\
\text { model PABSTE }\end{array}$} & \multicolumn{3}{|c|}{ Nucleeotide diversity (Pi) } & \multicolumn{3}{|c|}{ Per-site sequence error rate (Epsilon) } \\
\hline & & mean & SD & SE & mean & SD & SE \\
\hline Anthomastus sp & & 0.01295412 & & & 0.00290320 & & \\
\hline Corallium $s p$ & & 0.01467291 & & & 0.00258843 & & \\
\hline H. imperiale-laauense & & 0.01935775 & 0.01094005 & 0.00489254 & 0.00447727 & 0.00522005 & 0.00233448 \\
\hline Heteropolypus sp & & 0.01073423 & 0.00120338 & 0.00069477 & 0.00162720 & 0.00023350 & 0.00013481 \\
\hline P. alisonae & P. alisonae & 0.01279960 & & & 0.00205016 & & \\
\hline P. arborea & P. arborea & 0.01245029 & 0.00056582 & 0.00040010 & 0.00193813 & 0.00041487 & 0.00029336 \\
\hline P. arborea & P. pacifica & 0.01073423 & 0.00120338 & 0.00069477 & 0.00162720 & 0.00023350 & 0.00013481 \\
\hline P. coralloides & P. coralloides & 0.01245029 & 0.00056582 & 0.00040010 & 0.00193813 & 0.00041487 & 0.00029336 \\
\hline P. johnsoni & P. johnsoni & 0.01159218 & & & 0.00137491 & & \\
\hline P. kaupeka & P. kaupeka & 0.01241323 & 0.00175196 & 0.00087598 & 0.00229768 & 0.00048923 & 0.00024462 \\
\hline P. maunga & P. maunga & 0.01225252 & & & 0.00176518 & & \\
\hline P. stephencairnsi & P.sp.nov & 0.01290646 & 0.00280248 & 0.00198165 & 0.00229281 & 0.00093033 & 0.00065784 \\
\hline P. stephencairnsi & P. stephencairnsi & 0.01137950 & 0.00066172 & 0.00016543 & 0.00169174 & 0.00016364 & 0.00004091 \\
\hline S. cauliflora & & 0.01370341 & 0.00219709 & 0.00155358 & 0.00275104 & 0.00075783 & 0.00053587 \\
\hline
\end{tabular}


bioRxiv preprint doi: https://doi.org/10.1101/019745; this version posted May 24, 2015. The copyright holder for this preprint (which was not
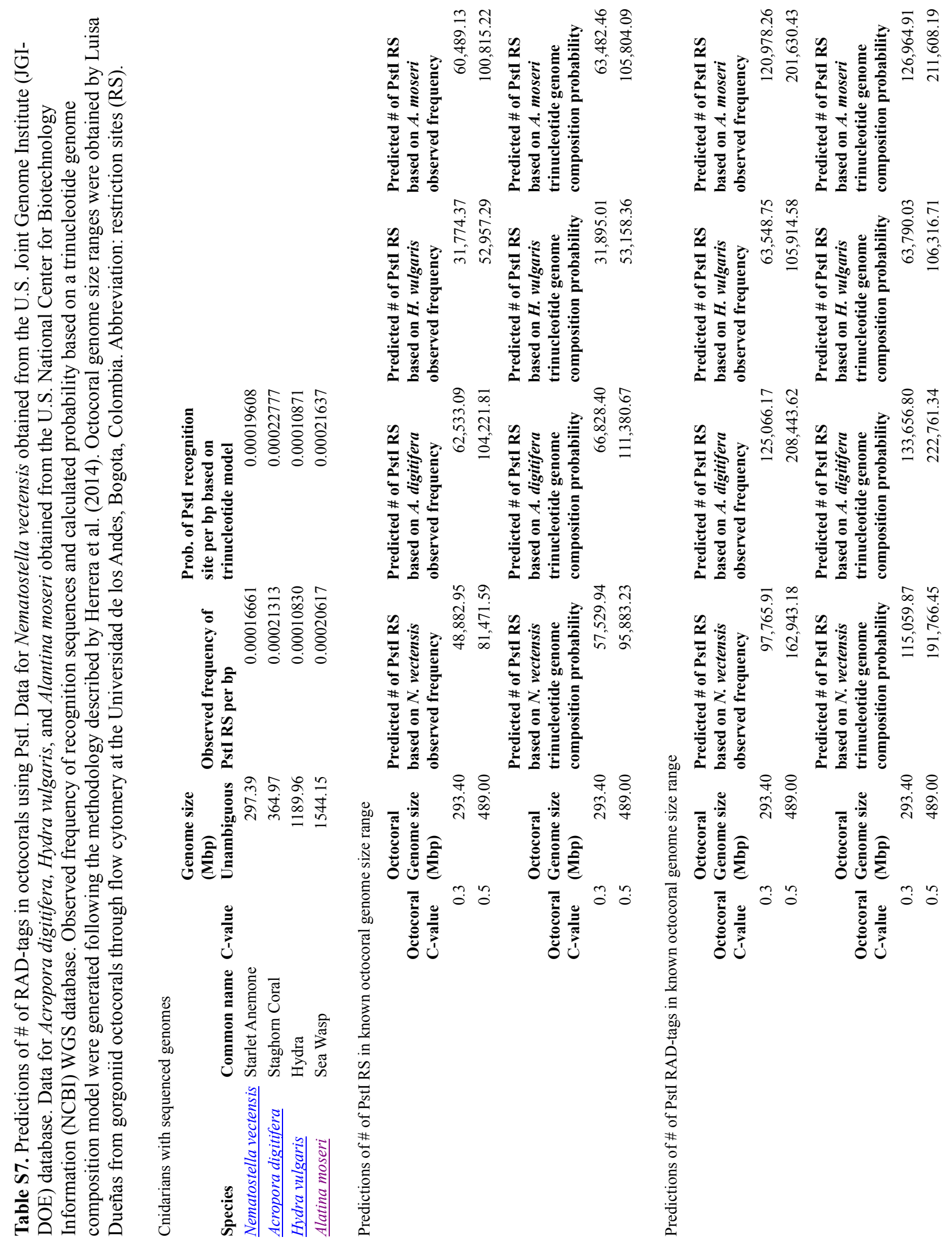


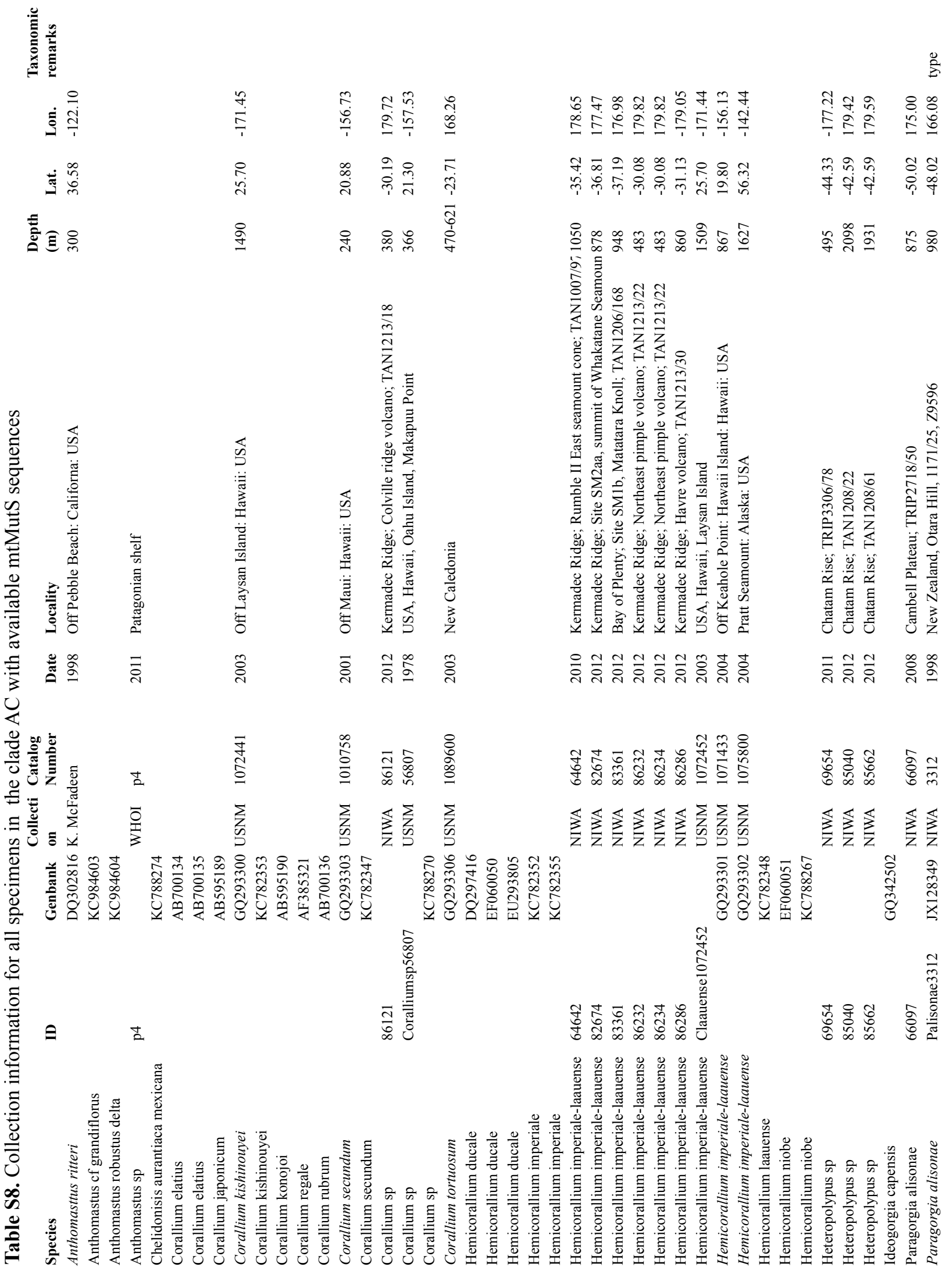


bioRxiv preprint doi: https://doi.org/10.1101/019745; this version posted May 24, 2015. The copyright holder for this preprint (which was not certified by peer review) is the author/funder, who has granted bioRxiv a license to display the preprint in perpetuity. It is made available under aCC-BY-NC-ND 4.0 International license.

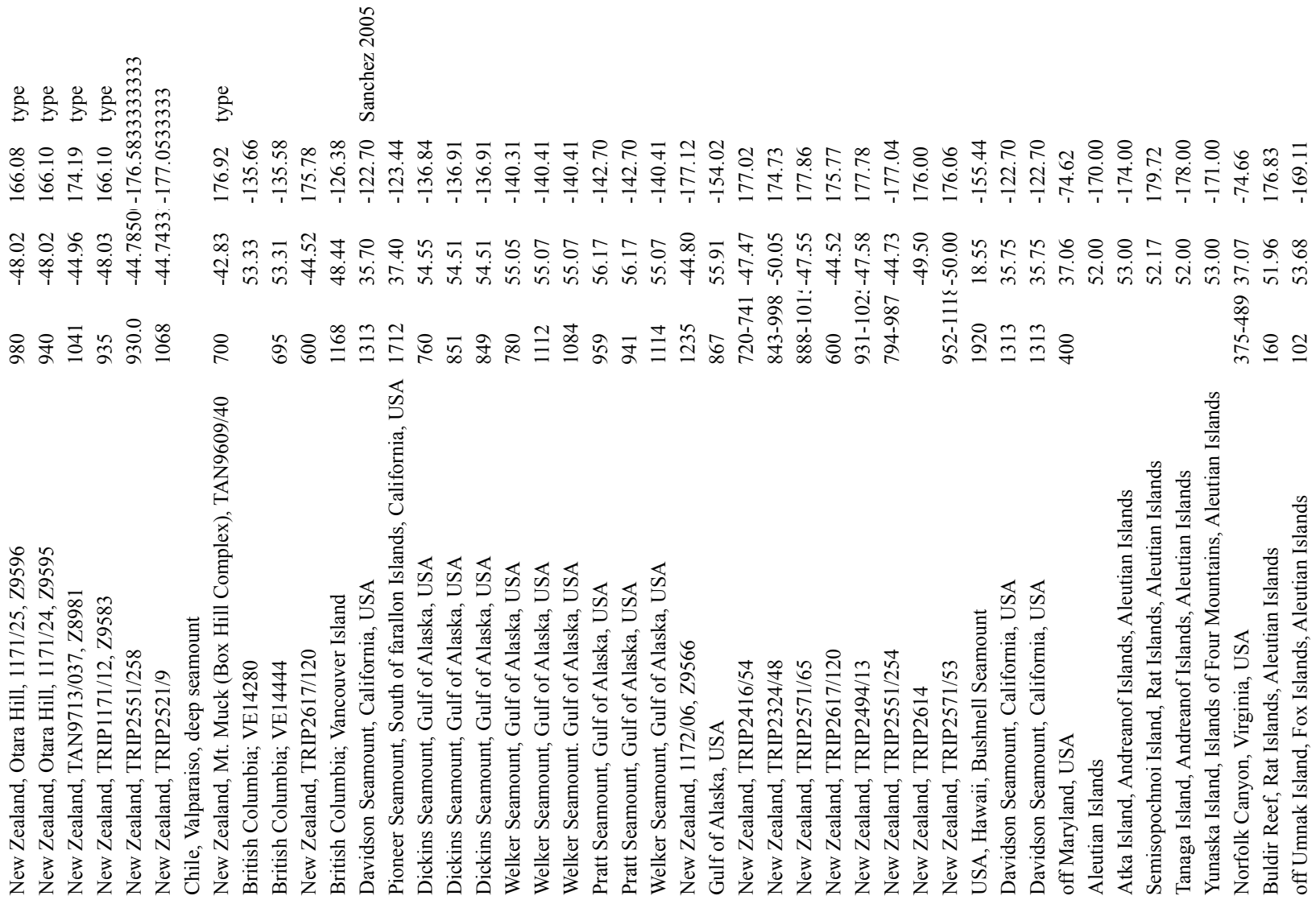

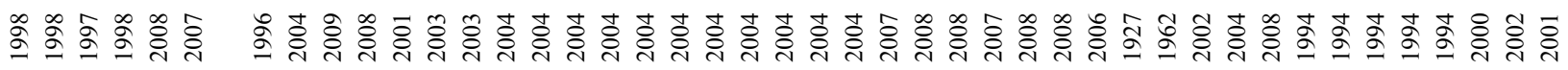

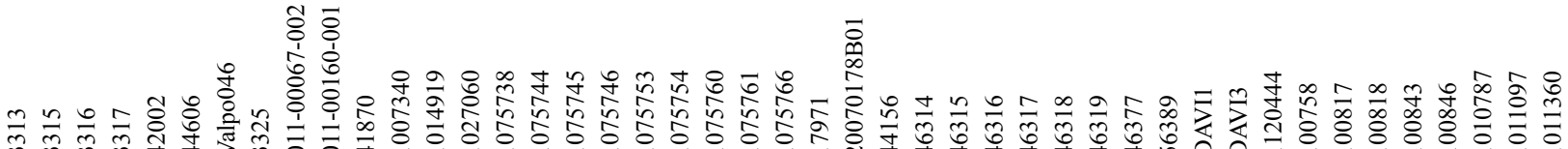

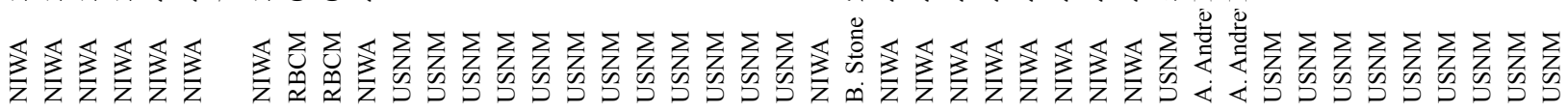

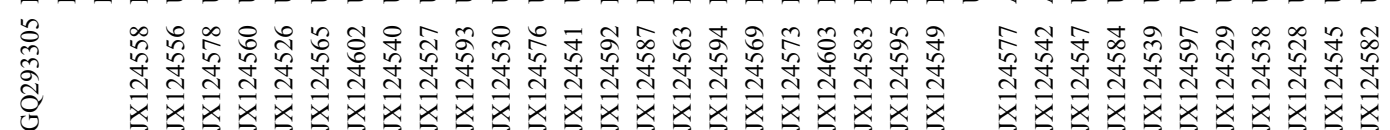

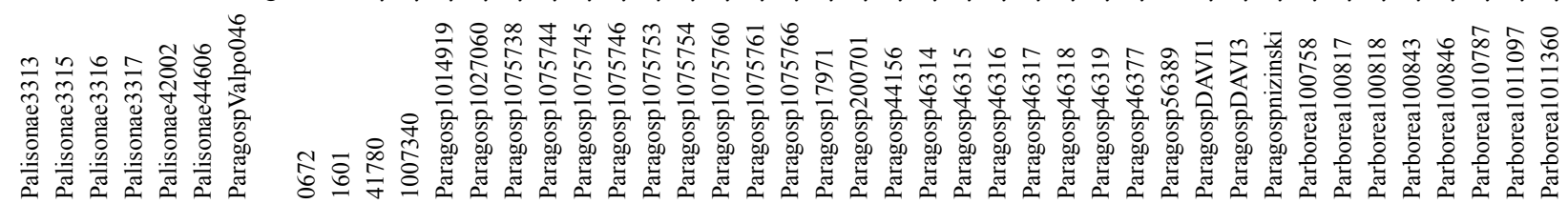

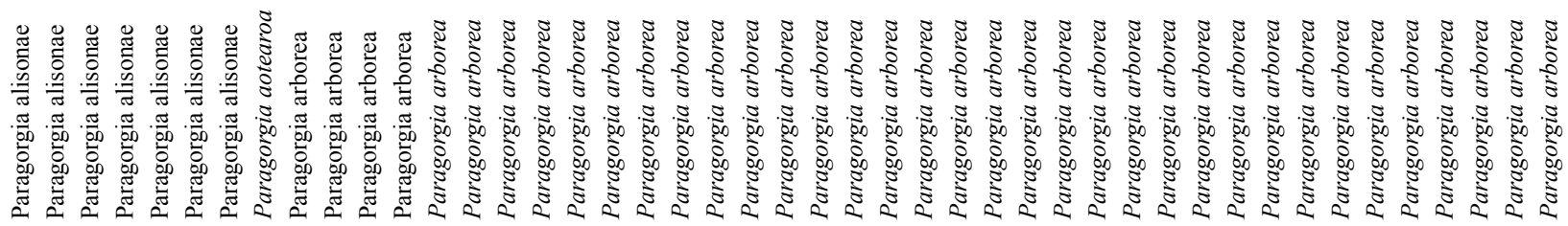


bioRxiv preprint doi: https://doi.org/10.1101/019745; this version posted May 24, 2015. The copyright holder for this preprint (which was not certified by peer review) is the author/funder, who has granted bioRxiv a license to display the preprint in perpetuity. It is made available under aCC-BY-NC-ND 4.0 International license.

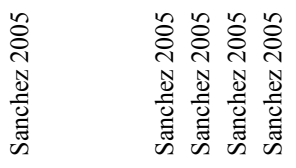

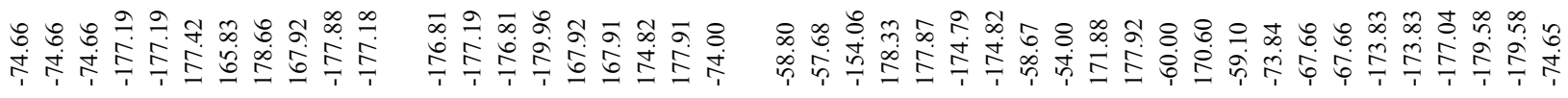

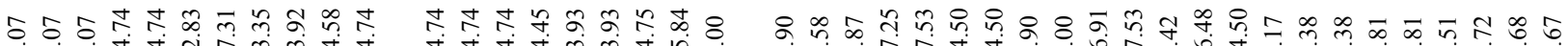

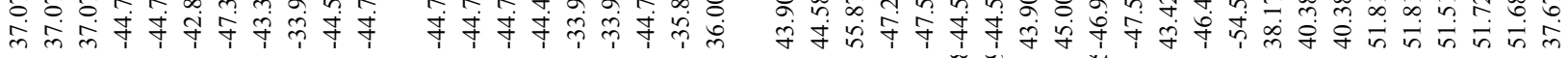
字 $\stackrel{+}{\dot{+}}$

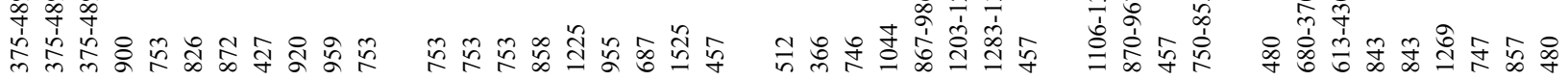

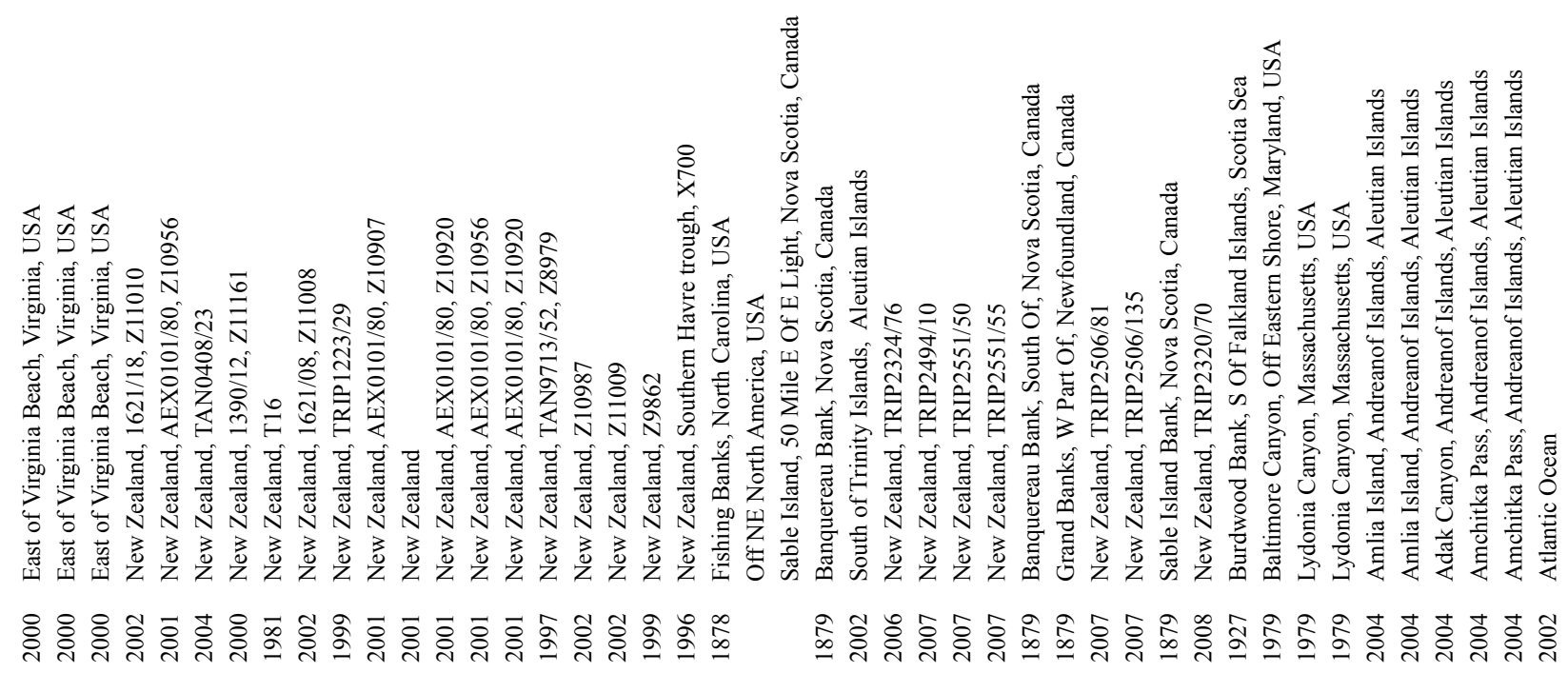

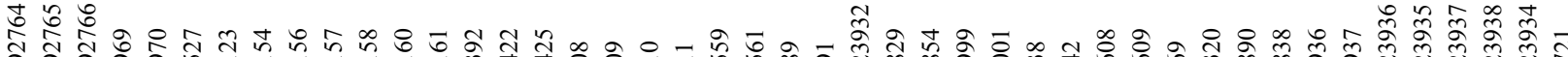

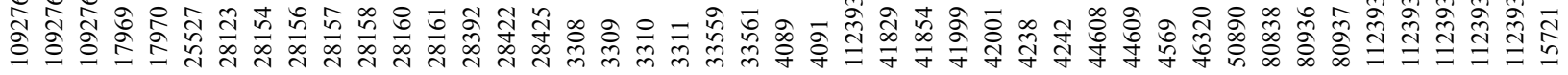

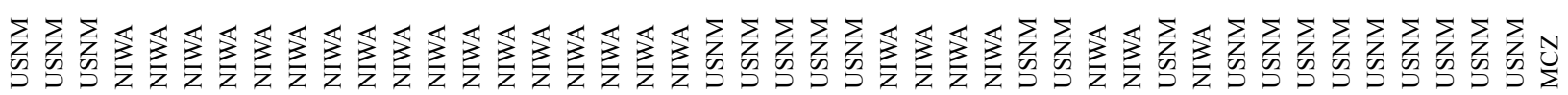

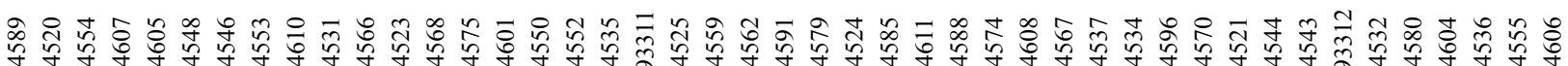

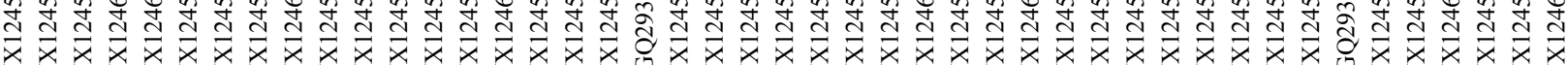

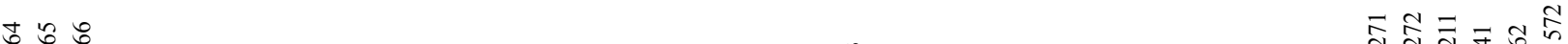

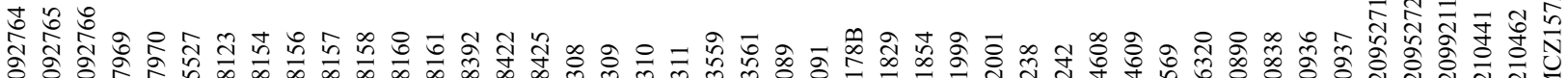
ॠ

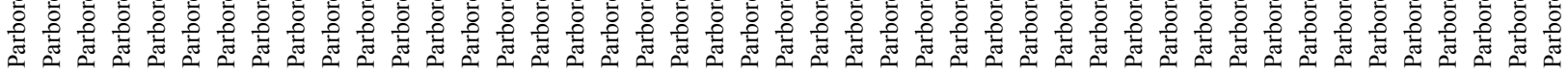

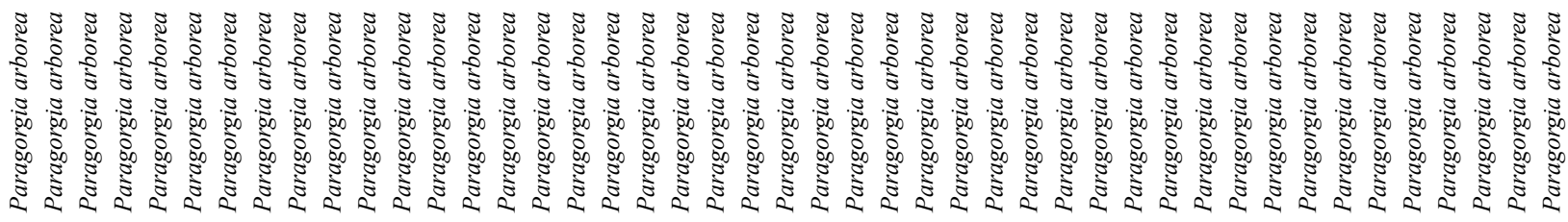


bioRxiv preprint doi: https://doi.org/10.1101/019745; this version posted May 24, 2015. The copyright holder for this preprint (which was not

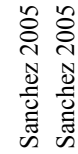

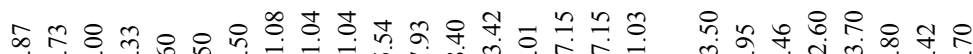

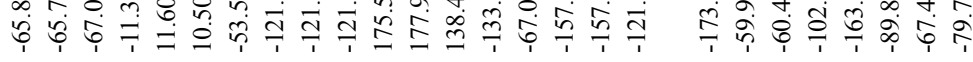

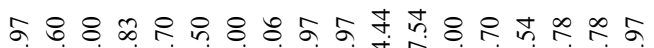

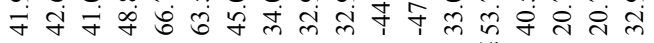

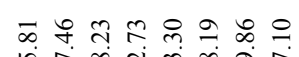

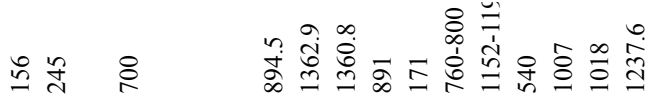

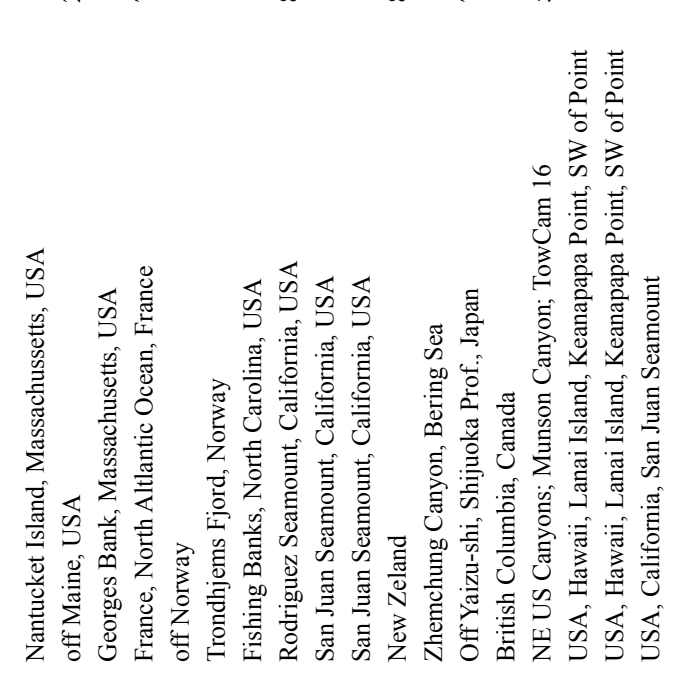

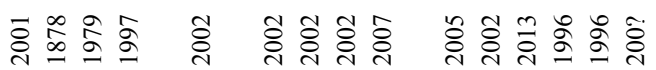

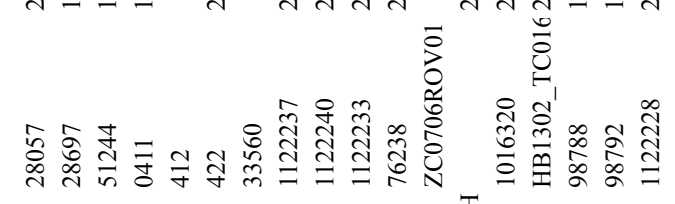
N

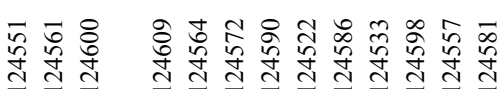

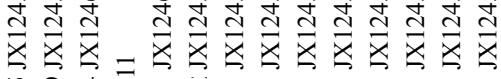

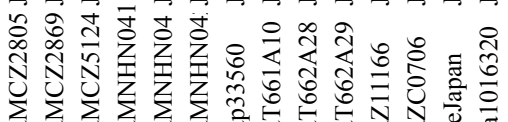

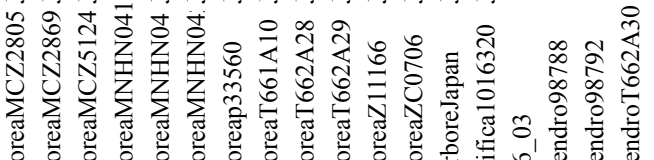

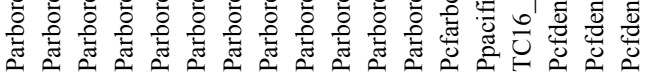

यें

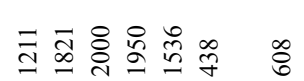

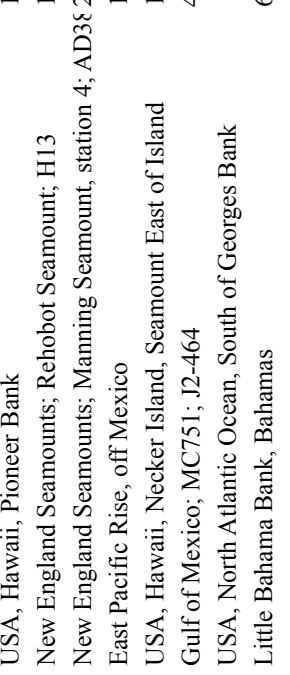

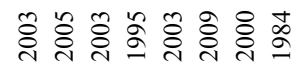

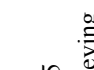

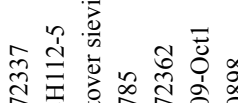

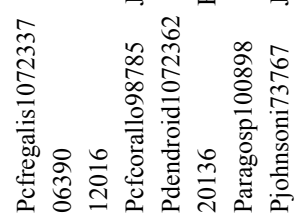
总总

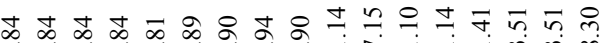

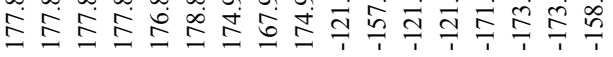

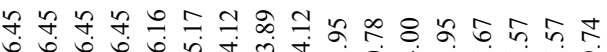

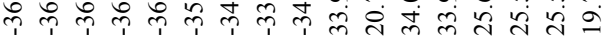

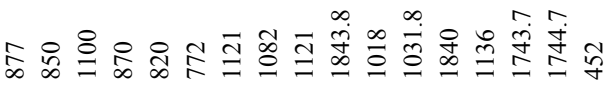

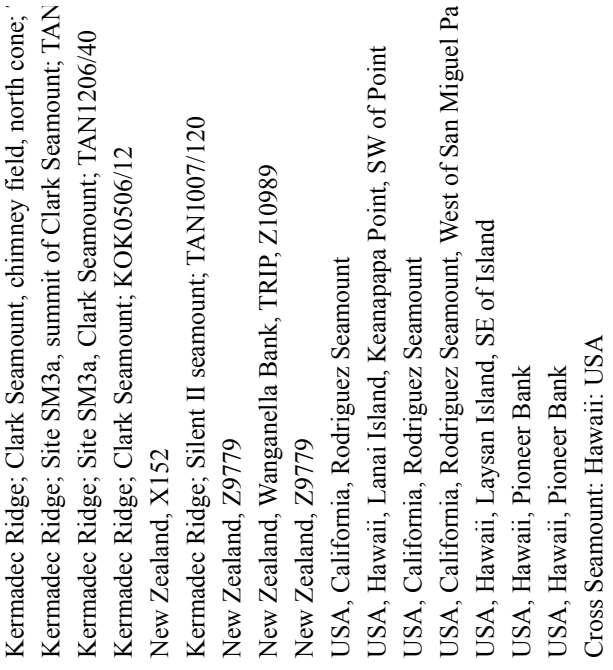

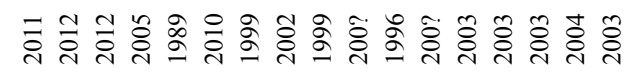

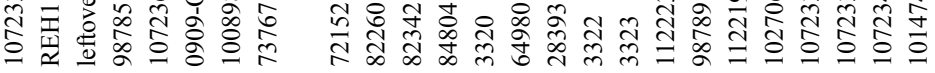

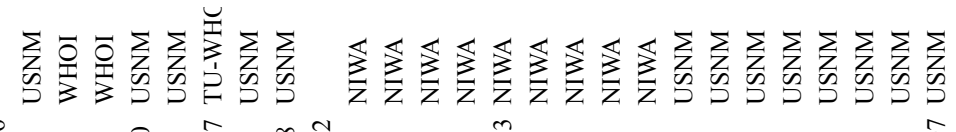

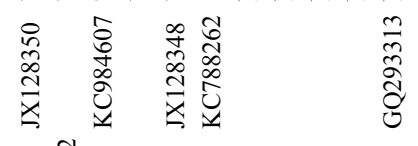
灾
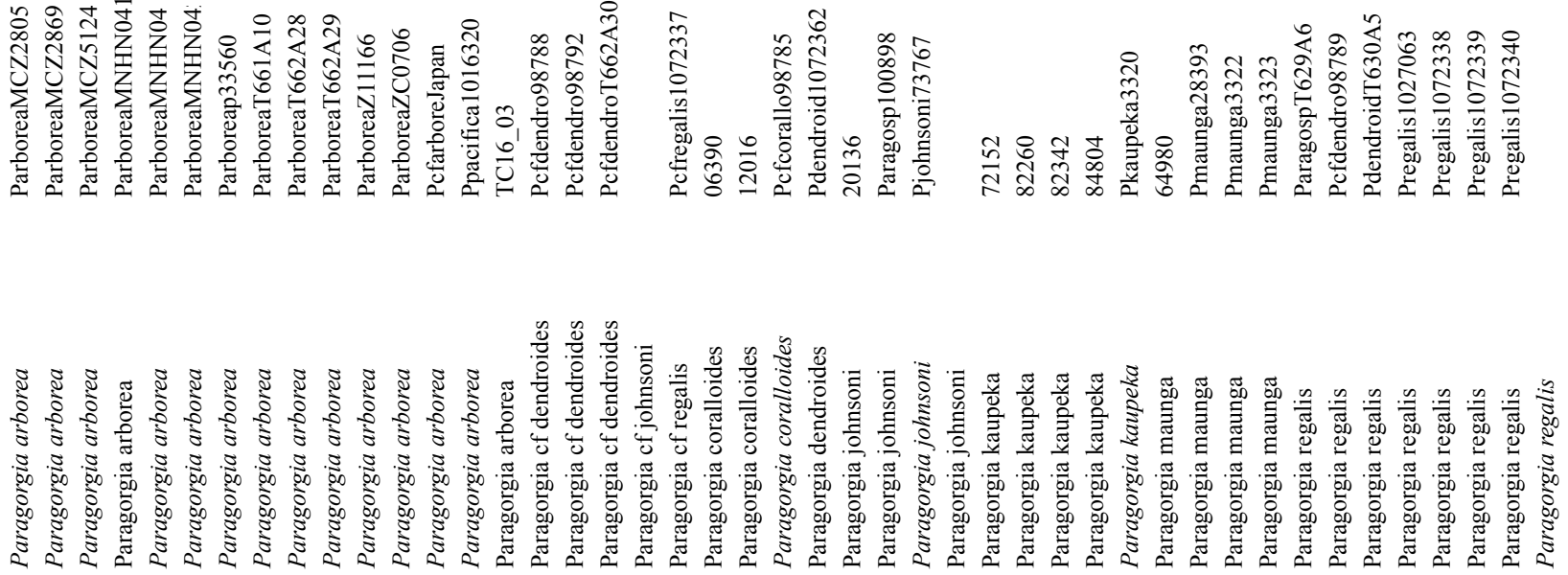
bioRxiv preprint doi: https://doi.org/10.1101/019745; this version posted May 24, 2015. The copyright holder for this preprint (which was not certified by peer review) is the author/funder, who has granted bioRxiv a license to display the preprint in perpetuity. It is made available under aCC-BY-NC-ND 4.0 International license.

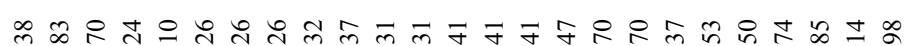

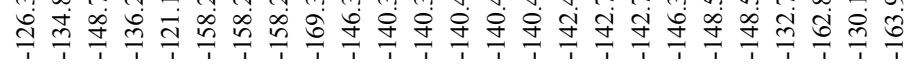

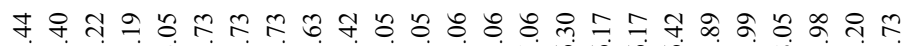

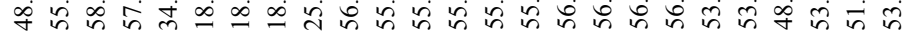

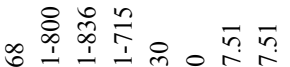

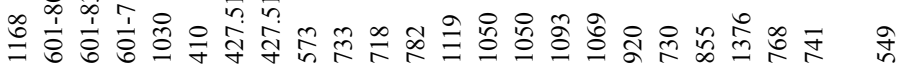
$\overline{\underline{a}} \approx$

范

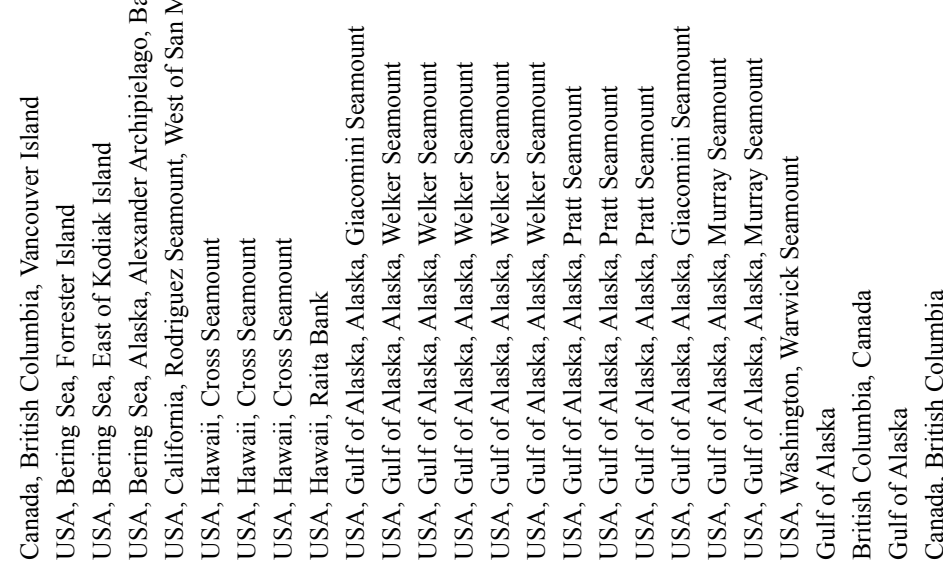

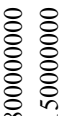

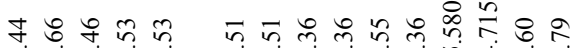

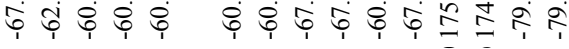
80

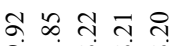
$\dot{m} \dot{m} \infty \prod_{\infty}^{\infty} \infty$

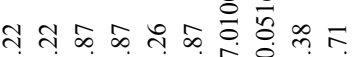
$\infty$ 少

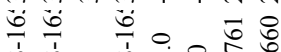

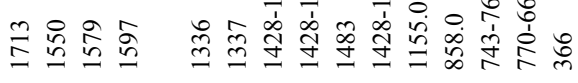

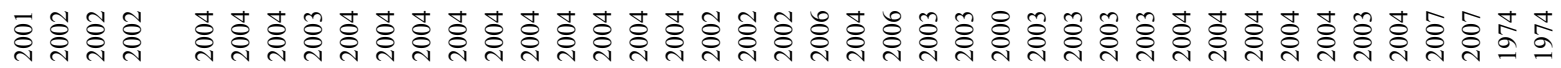

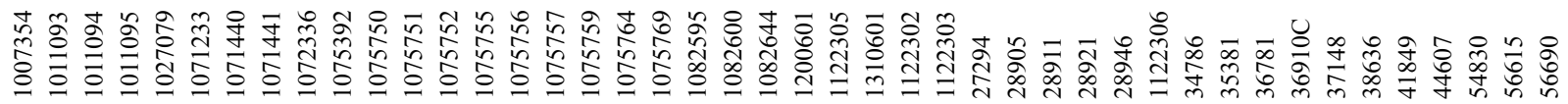

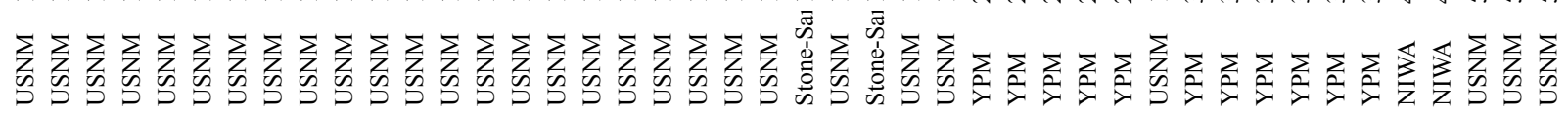

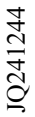

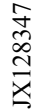

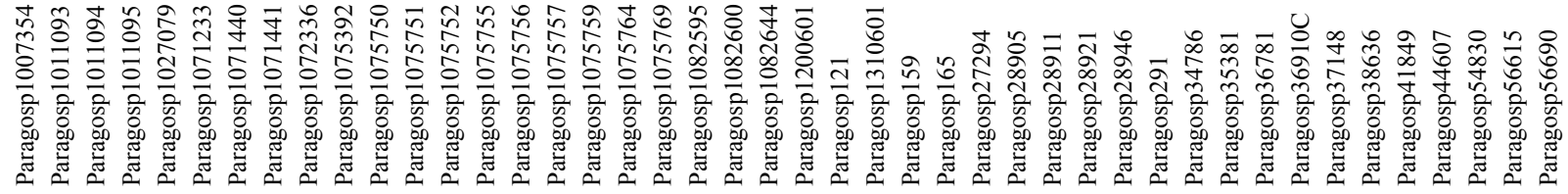

$\frac{n}{\pi}$

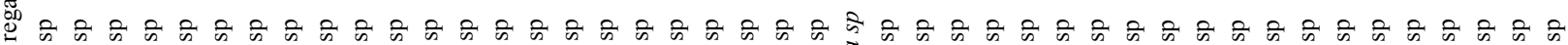

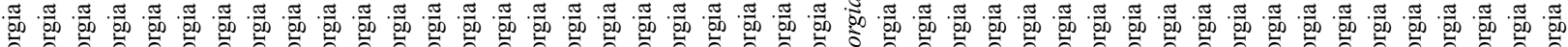

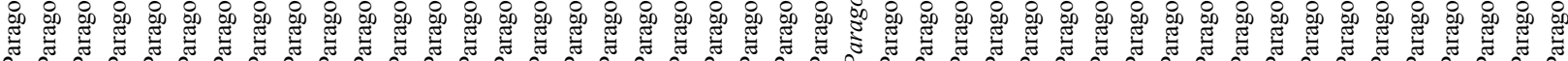


bioRxiv preprint doi: https://doi.org/10.1101/019745; this version posted May 24, 2015. The copyright holder for this preprint (which was not certified by peer review) is the author/funder, who has granted bioRxiv a license to display the preprint in perpetuity. It is made available under aCC-BY-NC-ND 4.0 International license.
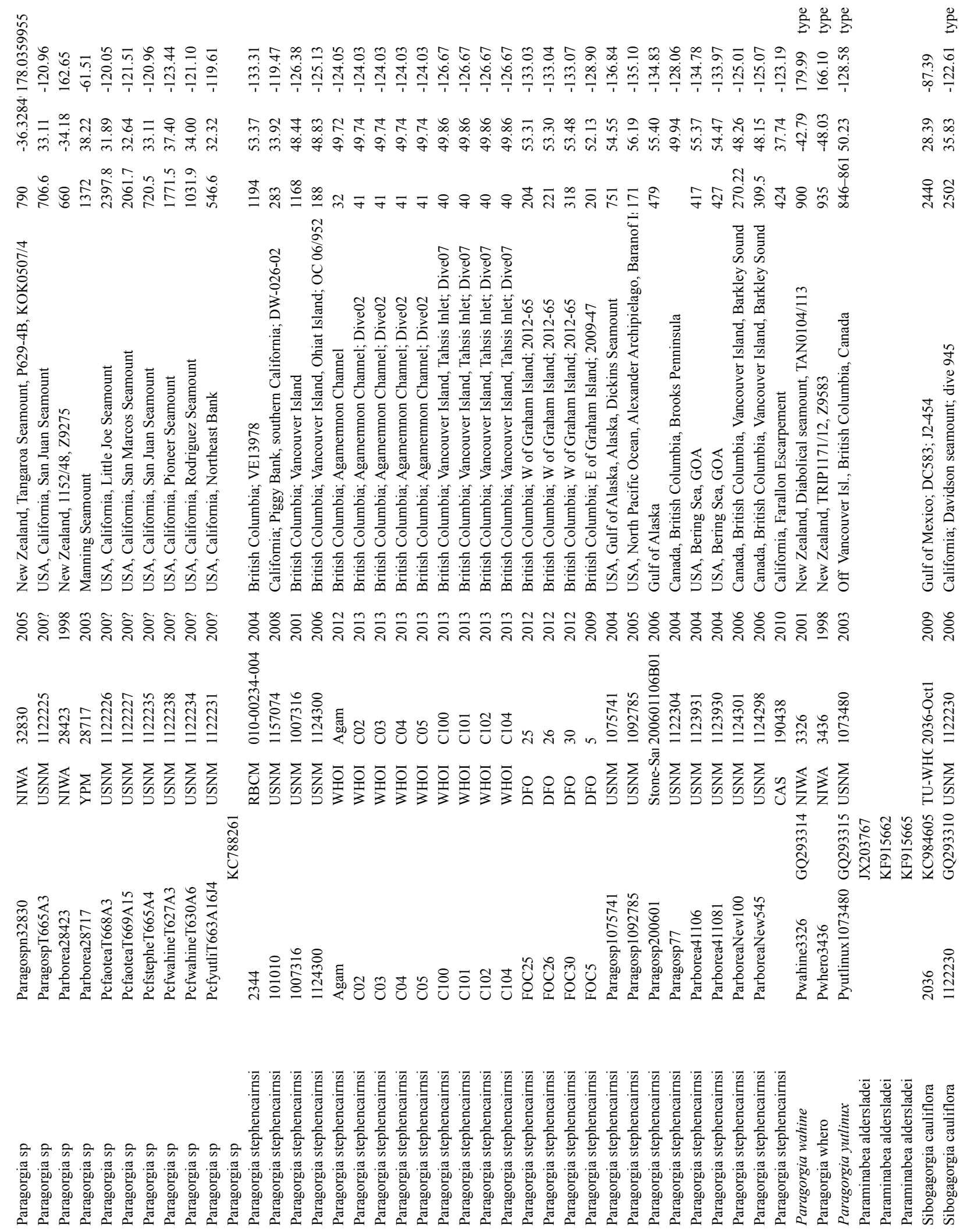


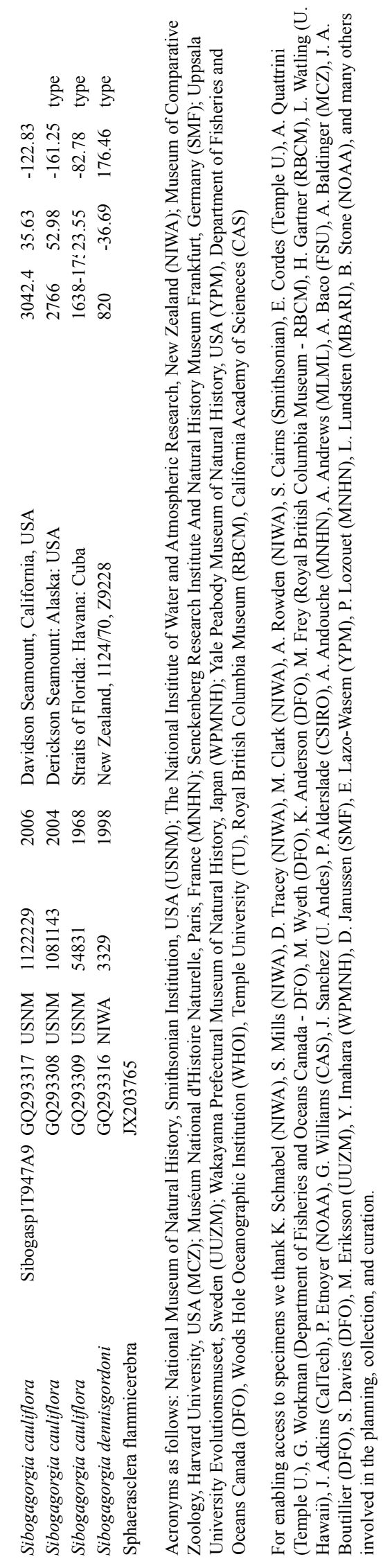

